This is a preprint of a paper of mine forthcoming in the Journal of General Philosophy of Science. Do not quote from this version, only from the final one. This paper mustn't be placed on other websites than these: http://logica.ugent.be/centrum/writings/pubs.php $\quad$ and http://philsciarchive.pitt.edu/. Appropriate actions will be undertaking, if necessary.

\title{
Understanding (in) Newton's Argument for Universal Gravitation
}

\author{
Steffen Ducheyne ${ }^{1}$
}

\begin{abstract}
In this essay, I attempt to assess Henk De Regt and Dennis Dieks recent pragmatic and contextual account of scientific understanding on the basis of an important historical casestudy: understanding in Newton's theory of universal gravitation and Huygens' reception of universal gravitation. It will be shown that de Regt and Dieks' CIT-criterion, which stipulates that the appropriate combination of scientists' skills and intelligibility-enhancing theoretical virtues is a condition for scientific understanding, is too strong. On the basis of this case-study, it will be shown that scientists can understand each others' positions qualitatively and quantitatively, despite their endorsement of different worldviews and despite their convictions as what counts as a proper explanation.
\end{abstract}

Keywords scientific understanding, H. de Regt, D. Dieks, theoretical virtues, Newton, Principia $(1687 ; 1713 ; 1726)$, universal gravitation, actio in distans, Huygens, Discours de la cause de la pesanteur (1690), spherical vortex cosmology, incommensurability

\section{Introduction: A Contextual Approach on Scientific Understanding}

Recently, Henk W. de Regt and Dennis Dieks (2005) have cogently pointed out that a philosophical analysis of scientific understanding should not only accommodate our contemporary scientific practice, but also account for the historical diversity of conceptions of scientific understanding. Whereas many philosophers of science seemed to have followed the view of Carl G. Hempel, according to which "understanding" is too subjective to be treated systematically (see: Trout 2002 and 2005), de Regt and Dieks have argued for a pragmatic and contextual approach intended to offer a general, but non-trivial, characterisation of scientific understanding. On their proposal, scientific understanding is epistemically relevant, since it belongs to the general, i.e. epistemic, aims of science (de Regt \& Dieks 2005, p. 139). Other epistemic aims of science include: production of knowledge supported by experience and, more precisely, prediction and description of natural phenomena. Besides obtaining

\footnotetext{
${ }^{1}$ The author is Postdoctoral Research Fellow of the Research Foundation Flanders (FWO-Vlaanderen). Contact: Centre for Logic and Philosophy of Science, Department of Philosophy and Moral Sciences, Ghent University, Blandijnberg 2, room 2.03, B-9000 Ghent, Belgium. Email: Steffen.Ducheyne@UGent.be. He is indebted to Eric Schliesser and George E. Smith to benefit from their forthcoming publication, to The Provosts and Syndics of Cambridge University Library for permission to quote from the Portsmouth and Maclessfield Collection, and to Helmut Pulte, Henk de Regt and the two anonymous referees of this journal for their valuable comments and suggestions. Convention for my transcriptions of Newton's manuscripts: arrows pointing downwards $(\downarrow \ldots \downarrow)$ indicate that the text in between them was inserted above Newton's original interlineation. Arrows pointing upwards $(\uparrow \ldots \uparrow)$ indicate that the text in between them was inserted under Newton's original interlineation. All other text-editorial features are as in the original.
} 
predictions and descriptions of phenomena (i.e., empirical adequacy), scientists typically seek to acquire understanding of how observed phenomena are derived from a theory which generates predictions and descriptions. A scientific theory is not merely a black box that produces empirically adequate knowledge: it needs to be shown how particular descriptions and predictions are generated. Thus, theoretical laws and principles by themselves will not do the job: what is further required are "particular skills of the user of this knowledge" (ibid., p. 142). The application of a theory to a natural system is typically not an algorithmic process. Having at one's disposal the relevant scientific theory is thus a necessary but not sufficient condition for establishing the epistemic aims of science.

While scientists agree on what the general aims of science are, they differ on the details and resources by which they seek to realize these aims. The actual establishment of the general aims of science depends on contextual factors, i.e. on whether a scientist possesses the appropriate skills to apply a theoretical tool - to which he attributes certain positive values (theoretical virtues) - to a set of phenomena belonging to its intended domain. To acquire scientific understanding, the right combination of scientists' skills and intelligibilityenhancing theoretical virtues is required. Note that both are not entirely subjective since they are acquired and assessed by a scientific community (ibid., p. 151).

Theories consist of general, abstract principles that govern the behaviour of a large set of phenomena; models are needed to apply these general principles to a number of different cases (Morgan \& Morrison 1999, p. 14). Consider Newton's second law of motion, for instance. From the second law (or, in fact, from all three) nothing much of interest follows (Giere, 1988, p. 66). We need additional information provided by a model (e.g., a two bodysystem, a simple pendulum, etc.) to actually represent a physical system. According to Ronald $\mathrm{N}$. Giere, the laws of mechanics are like "general schemas that need to be filled in with a specific force function in order to carry information about the world" (ibid., p. 76 [italics added]). A scientist, therefore, needs to find ways of supplementing additional information which allows for the application of abstract theory to physical systems. Since model construction is typically not a deductive process, it will demand considerable creativity and ingenuity on behalf on the scientist to bridge the gap between abstract theory and brute facts.

Scientific theories function as conceptual toolboxes by means of which we interpret phenomena. Whether scientists are able to apply a theory to a given phenomenon will, besides on their ability to apply this theory, depend on the pragmatic virtues of a theory (e.g., simplicity, continuity, unifying power, causal explanation, visualization, etc.). Such virtues "may contribute to the intelligibility of the theory, thereby facilitating the use of theory in the construction and application of models" (de Regt \& Dieks 2005, p. 142). Whether a theory is considered (un-)intelligible will depend on the pragmatic virtues of the theory and on "such contextual factors as the capacities, background knowledge and background beliefs of the scientists in [context] C" (ibid., p. 151). Intelligibility is a positive value projected onto a theory by scientists (de Regt 2004, p. 103) in function of a scientist's background knowledge and his skill to work with the theory. De Regt and Dieks then provide a criterion for the intelligibility of a theory:

Criterion of the Intelligibility of a Theory: A scientific theory $T$ is intelligible for scientists (in context $C$ ) if they can recognise qualitatively characteristic consequences of $T$ without performing exact calculations. (De Regt \& Dieks 2005, p. 151) ${ }^{2}$

A theory provides understanding, if it is intelligible, i.e. if it gives us an intuitive grasp of the phenomena "before we embark on detailed calculations" (ibid., pp. 152-153). De Regt and

\footnotetext{
${ }^{2}$ In private communication Henk De Regt has confirmed that this criterion is intended only to account for the first step in the process of understanding of a theory (19 May 2007, Leusden).
} 
Dieks further note that "such calculations are subsequently motivated, and given direction, through the understanding we already possess" (ibid., p. 153) and that analogous "to problemsolving heuristics, the 'intuitive' recognition of theoretical consequences requires conceptual tools" (ibid., p. 155).

Rather than arguing against their views, I seek to suggest some modifications or extensions to their original proposal on the basis of an important historical case-study: understanding in Newton's theory of universal gravitation. Before turning to Newton's argument for universal gravitation proper, I shall address two potentially controversial issues in section 2: the causal status of centripetal forces (2.1) and Newton's views on actio in distans (2.2). In section 3, I shall discuss the analytical part of Newton's argument for universal gravitation proper. In section 4, I shall take stock of the implications of the historical case-study at hand for de Regt and Dieks' proposal by focussing on Christiaan Huygens' reception of the theory of universal gravitation.

\title{
2. Newton: Preliminary Clarifications
}

Before turning to the analytical part of Newton's argument for universal gravitation, I shall address two potentially controversial issues: (2.1) the nature of causation in the Principia and (2.2) Newton's views on actio in distans.

\subsection{Centripetal Forces as Causes}

There is a "Janus-like ambiguity" to the central concepts in the Principia: force, attraction, and gravity (McMullin 1990, p. 72). They appear to be "purely mathematical" as well as causal. How can this ambiguity be explained? How are we to make sense of this tension inherent to Newton's work? Despite Newton's frequent causal talk in his published works (see Ducheyne 2005a and 2006 for examples), the Principia also seems to contain positivistic sounding statements. In a comment to Definition VIII Newton warns his readers that he is not "considering the physical causes and sites of forces" ("virium causas \& sedes physicas"):

\begin{abstract}
Moreover, I use interchangeable and indiscriminately words signifying attraction, impulse, or any sort of propensity toward a center, considering these forces not from a physical but only from a mathematical point of view. Therefore let the reader beware of thinking that by words of this kind I am anywhere defining a species or mode of action of a physical cause or reason, or that I am attributing forces in a true and physical sense to centers (which are mathematical points) if I happen to say that centers attract or that centers have forces. (Newton 1999 [1726], p. 408 [italics added], cf. ibid., p. 588)
\end{abstract}

In this passage Newton dispensed with an agent-causal interpretation of attraction, where one attributes real causal agency to the centre of a body. However, as I will argue in what follows, this statement should not be seen as a refusal to establish causes and real forces, but rather as a caveat not to consider the centres of bodies as being the real physical seat of the attracting force, and moreover, as a refusal to discourse about the cause of gravity. ${ }^{3}$ Situating the force

\footnotetext{
${ }^{3}$ On CUL 3968, f. $584^{\mathrm{r}}$ [ca. 1712-1713], Newton wrote that is was his intention of writing the above quote was to remain "silent about the cause of gravity, there occurring no experiments or phænomena by $w^{\text {ch }}$ he might prove what was the cause thereof: And this he hath abundantly declared in his Principles neare the beginning thereof in these words; Virium causas et sedes Physicas jam non expendo. And a little after: Voces attractionis, impulsus vel propensionis cujusque in centrum indifferenter \& pro se mutuo promiscue usurpo, has vires non physice sed mathematice tantum considerando. Unde caveat Lector ne per hujusmodi voces cogitet me speciem vel modum actionis, causamve aut rationem physicam alicubi definire, vel centris (quæ sunt puncta Mathematica) vires vere et physice tribuere, si forte aut centra trahere aut vires centrarum esse dixero."
} 
of attracting at the centre of a sphere is a convenient mathematical operation to approximate the overall force of an attracting spherical body, which in fact results from each particle constituting the body (see section 3), but it is not to be taken literally, i.e. one should not "attribute force in a true and physical sense to centers". Andrew Janiak has recently concluded that "'[g]ravity' refers to whatever it is that non-mechanically causes various motions of bodies near the surface of the Earth, of our oceans, and of the heavenly bodies, in such a way that distance and mass are the salient variables in their changes in states of motion" (Janiak 2007, p. 143; Janiak 2008, pp. 74-75, pp. 76-77). Although this is basically correct, here I seek to elaborate on the sort of causality involved. Before doing so, I would like to stress that I. Bernard Cohen's "Newtonian Style" is compatible with a causal reasoning of the Principia. Cohen states that, in commenting on Propositions I-III, Book I, Newton had demonstrated that a mathematically descriptive law of motion was shown by mathematics to be equivalent to a set of causal conditions of forces and motions (Cohen 1982 , p. 28, cf. p. 37). Given that the laws of motion are valid, Newton was able to deduce that the area law is caused by its necessary and sufficient causal condition: a centripetal force (ibid., p. 63). The "Newtonian Style" thus perfectly allows reasoning from effects to causes.

Newton introduced a new causal entity, "universal gravitation", which was completely different from a mechanical notion of cause in term of direct contact (Ducheyne, 2005a). He did not, like many of his contemporaries (e.g., Leibniz and Huygens) endorse the customary form of causal explanation, namely mechanistic explanations (Newton 1999 [1726], p. 940). By means of abstract physico-mathematics he was able to demonstrate that the force of gravity is the cause of the celestial and terrestrial motions. The novelty involved in Newton's explanations baffled most of his contemporaries (Iliffe 2004, p. 439) and continues to do so.

Once Gottfried W. Leibniz had publicly criticised Newton for introducing a qualitas occulta $^{4}$, i.e. gravity, into natural philosophy, Newton became increasingly pressed to clarify the kind of explanation he had offered in the Principia and to clarify his method of philosophizing from a methodological point of view (on the latter see: Shapiro 2004). The crux of Newton's solution for meeting this public criticism lay in carefully distinguishing between different "levels of causation": phenomena are caused by proximate causes, which are in their turn caused by remote causes. Hence, Newton declared that "the main Business of natural Philosophy is to argue from Phaenomena without feigning Hypotheses, and to deduce Causes from Effects, till we come to the very first Cause, which is certainly not mechanical" (Newton 1979 [1730], p. 369). In manuscript material dating from around 1712-1713, Newton was more precise: in natural philosophy one argues "from Phæ $\downarrow$ no $\downarrow$ mena \& Experiments, $\downarrow$ first $\downarrow$ to the causes thereof, \& $\downarrow$ thence $\downarrow$ to the causes of those causes, \& so on till we come to the first cause" (CUL Add. Ms. 3968, f. 586 ; cf. f. $27^{\mathrm{r}}$ ). In the Principia, Newton had only provided explanations involving the proximate causes of orbital motion

\footnotetext{
${ }^{4}$ See Leibniz' defence of a mechanical ether composed of bullae in his Hypothesis Physica Nova (1671) in: Gerhardt (ed.) 1849-1863, VI, pp. 17-59, his Tentamen de motuum coelestium causa (1689), in ibid., VI, pp. 144-187, and his De causa gravitatis, et defensio sententia authoris de veris natura legibus contra Cartesianos (1690), in ibid., VI, pp. 193-203. In an unpublished letter addressed to the editor of The Memoirs of Literature (ca. May 1712) Newton defended himself as follows to Leibniz's critique: "Because they do not explain gravity by a mechanical hypothesis, he charges them with making it a supernatural thing, a miracle and a fiction invented to support an ill-grounded opinion and compares their method of philosophy to that of $\mathrm{Mr}$. de Roberval's Aristarchus, which is all one as to call it romantic [i.e. fictional]. They show that there is a universal gravity and that all phenomena of the heavens are the effect of it and with the cause of gravity they meddle not but leave it to be found out by them that can explain it, whether mechanical or otherwise. [...] And therefore if any man should say that bodies attract one another by a power whose cause is unknown to us, or by a power seated in the frame of nature by the will of God, or by a power seated in a substance in which bodies move and float without resistance and which has therefore no vis inertiae but acts by other laws than those that are mechanical: I know not why he should be said to introduce miracles and occult qualities and fictions into the world." (Janiak (ed.) 2005, pp. 115-116).
} 
(centripetal forces), while he deliberately neglected from the remote causes (the cause of gravity), or so I will argue. In the published General Scholium, Newton famously wrote:

Thus far I have explained the phenomena of the heavens and of our sea by the force of gravity, but I have not yet assigned a cause to gravity. Indeed, this force arises from some cause that penetrates as far as the centers of the sun and planets without diminution of its power to act, and that acts not in proportion to the quantity of the surfaces of the particles on which it acts (as mechanical causes are wont to do) but in proportion to the quantity of solid matter, and whose action is extended everywhere to immense distances, always decreasing as the squares of the distances. [...] And it is enough that gravity really exits and acts according to certain laws that we have set forth and is sufficient to explain all the motions of the heavenly bodies. (Newton 1999 [1726], p. 943)

Newton took the above statement to mean that he had proved gravity as a primary or proximate cause for the heavenly and terrestrial motions, but that he did not succeed in discovering a further secondary or remote cause for gravity. Nevertheless, an explanation referring exclusively to the primary cause (and neglecting the secondary mechanism - if any causing it) was fully legitimate to his mind. In CUL Add. Ms 9597.2 (ca. 1712-1713), Newton thought the consequences of not accepting such "partial" explanations through: this would imply - a view impossible for Newton to accept - that the only satisfactory explanations were "causally complete", i.e. that they fully explain all causal agents occurring in between the observed phenomena and the ultimate cause:

Otherwise, altogether no phenomenon could rightly be explained by its cause, unless the cause of this cause and the cause of the prior cause were to be exposed and so successively [and] continuously until the primary cause is arrived at. (CUL Add. Ms. 9597.2.11, f. $\left.3^{\mathrm{r}}\right)^{5}$

Newton thought that such "partial" explanations were perfectly legitimate, for he wrote:

And to understand this without knowing the cause of gravity, is as good a progress in philosophy as to understand the frame of a clock $\&$ the dependence of $\mathrm{y}^{\mathrm{e}}$ wheels upon one another without knowing the cause of the gravity of the weight which moves the machine is in the philosophy of clockwork, or the understanding the frame of the bones \& muscles by the contracting or dilating of the muscles without knowing how the muscles are contracted or dilated by the power of $\mathrm{y}^{\mathrm{e}}$ mind is [in] the philosophy of animal motion. (Newton to the Editor of Memoirs of Literature, after 5 May 1712, Turnbull e.a. (eds.) (1959-1977), V, p. 300 [italics added])

In CUL Add. Ms 3965.9 (ca. 1712-1713), Newton explicitly articulated his views on explanation by means of distinguishing between proximate and remote causes:

He who investigates the laws and effects of electric forces with the same success and certainty will greatly promote philosophy [i.e., natural philosophy], even if perhaps he does not know the cause of these forces. First, the phenomena should be observed, then their proximate causes - and afterward the causes of the causes - should be investigated, and finally it will be possible to come down from the causes of the causes (established by phenomena) to their effects, by arguing a priori. Natural philosophy should be founded not on metaphysical opinions, but on its own principles and [end of text] (Newton 1999 [1726], pp. 53-54) ${ }^{6}$

\footnotetext{
${ }^{5}$ Author's translation of: “Alias nullum omnino phaenomenon $\downarrow$ per causam suam $\downarrow$ recte explicari posset nisi causa ejus $\downarrow$ hujus $\downarrow$ causae, \& causa priori causae prioris redderetur \& sic deinceps usque donec ad causam primam deventum sit."

${ }^{6}$ Cohen's translation of: "Qui leges et effectus Virium electricarum pari successu et certitudine eruerit, philosophiam multum promovebit, etsi $\downarrow_{\text {forte }} \downarrow$ causam harum Virium ignoraverit. Nam Phaenomena $\downarrow_{\text {observanda }} \downarrow$ primo $\downarrow_{\text {spectanda }} \downarrow$-consideranda $\downarrow_{\text {sunt }} \downarrow$, dein horum causae proximae, \& postea causae causarum ertenda eruenda; ac tandem a causis $\downarrow$ supremis causarum $\downarrow$ per phaenomena stabilitis, ad $\downarrow$ eatusas $\downarrow$ eatus phaenena $\downarrow$ eorum effectus $\downarrow$, $\downarrow$ eorum catsas proximas $\downarrow$ argumentando a priori, descendere licebit. Et inter Phaenomena numerandae sunt actiones mentis quae nobis innotescunt quarum conseij sumus Philosophia
} 
Natural philosophy proceeds from phenomena to proximate causes, then from proximate causes to remote causes, and then finally - a priori $^{7}$ - from remote causes to proximate causes. It is especially in this manuscript material that Newton's hierarchical account of causal explanation is apparent.

In Propositions I-II, Newton argued that a centripetal force is a necessary and sufficient causal condition for the planarity of the orbit and Kepler's area rule, i.e. he argued that the areas of a body described by radii drawn to an unmoving centre of force lie in a fixed plane and are proportional to the times (deductive direction 1; sufficient cause), and, conversely, that a body, which moves along a curved line described in a plane and by a radius drawn to a point describes areas about that point that are proportional to the times, is urged by a centripetal force tending toward that point (deductive direction 2 ; necessary cause). Proposition I states:

The areas which bodies made to move in orbits describe by radii drawn to an unmoving center of forces lie in unmoving planes and are proportional to the times. (Newton 1999 [1726], p. 444)

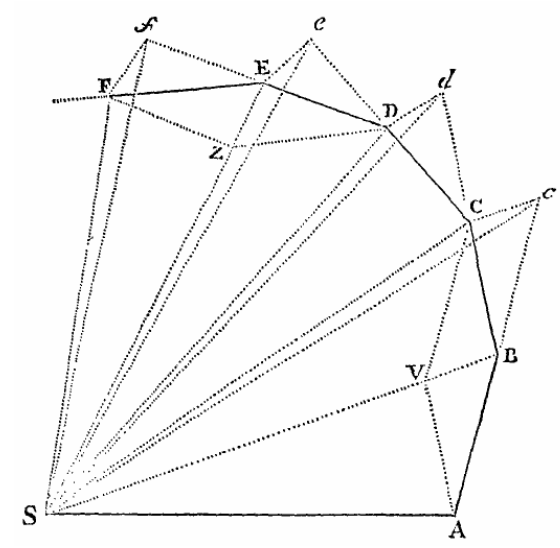

Figure 1. Original figure accompanying Proposition I. Reproduced from Newton, I. (1726). Principia mathematica philosophiae naturalis. London: Guil. \& Joh. Innys for the Royal Society, p. 40. Courtesy of The Royal Society.

Its proof proceeds as follows (see figure 1). First, Newton divided the time into equal parts. Let, furthermore, $c \mathrm{C}$ be parallel to $\mathrm{BS}$ and meet $\mathrm{BC}$ at $\mathrm{C}$. In the first part of time a body describes by its inherent force the straight line $\mathrm{AB}$. In the second part of time the body would, by Law I, go straight on to $c$ describing $\mathrm{B} c$, but, as it orbits around $\mathrm{S}$ (by hypothesis), it is deflected from its original rectilinear inertial path by a centripetal force acting along BS (by Corollary $1^{8}$ to the laws of motion) and describes BC. Then body will be found at $\mathrm{C}$ in the same plane as triangle ASB. Since SB and $\mathrm{C} c$ are parallel, triangle $\mathrm{SBC}$ will be equal to $\mathrm{SB} c$ (since both their height and base is equal) and thus to SAB. Hence the body describes an equal area in an equal amount of time. By similar argument this can be extended to all triangles of the polygon. Newton then argued that, if the number of triangles as well as their width is increased infinitely ("augeatur jam numerus \& minuatur latitudo triangulorum in infinitum") and, correspondingly, their ultimate perimeter ADF will be curved (by Corollary 4 to Lemma III (Newton 1999 [1726], p. 434), a body perpetually drawn ("perpetuò tetrahitur")

naturalis non in opinionibus Metaphysicis, sed in Principiis propijs fundanda est; \& haec [end of text]" (CUL Add. Ms. 3970, f. 109 ${ }^{\mathrm{v}}$ ).

7 "A priori" here means what comes first in the order of nature; "a posteriori" means what comes first in the order of knowing.

${ }^{8}$ Which states: "A body acted on by [two] forces acting jointly describes the diagonal of a parallelogram in the same time in which it would describe the sides if the forces were acting separately." (Newton 1999 [1726], p. 417). 
back from the tangent of the curve by a centripetal force towards $\mathrm{S}$ will describe equal areas in equal times. In this way, Newton reduced a discontinuous motion along the sides of a polygon is thus to a continuous motion along a smooth orbital path. ${ }^{9}$

Let us now turn to Proposition II:

Every body that moves in some curved line described in a plane and, by a radius drawn to a point, either unmoving or moving uniformly forward with a rectilinear motion, describes areas around that point proportional to the times, is urged by a centripetal force tending toward that same point. (Newton 1999 [1726], p. 446)

Proposition II, which Newton introduced for the first time in the initial revise of De motu (Whiteside (ed.) 1967-1981, VI, pp. 124-127), amounts to stating that an orbiting body describing equal areas in equal times necessarily requires a centripetal force exerted on that body. Thus, it sets out to demonstrate the converse of Proposition I. The proof proceeds as follows (again see figure 1). By Law I we know that a body that moves in a curved line is deflected from a rectilinear course by some force acting on it. Then, by Law II, the force by which the body is deflected from rectilinear course and in equal times is made to describe around an immovable point $S$ the equal minimally small triangles $\mathrm{SAB}, \mathrm{SBC}, \mathrm{SCD}$, etc. acts at $\mathrm{B}$ along a line parallel to $c \mathrm{C}$, i.e. along the line $\mathrm{BS}$; at place $\mathrm{C}$, parallel along the line $d \mathrm{D}$, i.e. along CS, etc. Therefore, it always acts along lines tending towards $\mathrm{S}$ - here Newton again presupposed the equivalence between a continuous force and its corresponding limit of discontinuous impulsive forces. ${ }^{10}$ By Corollary $5^{11}$ this holds for both a one-body system at rest or describing uniform and rectilinear motion. Propositions I-II thus jointly establish that:

Centripetal force by which a body is to an unmoving centre of force is directed exactly to this centre, if and only if, that body describes equal areas, which lie in a fixed plane, in equal times exactly.

In Corollaries 2-3 to Proposition III, Newton showed that an overall centripetal force directed quam proxime, i.e. very nearly, to its attracting centre is a necessary and sufficient

\footnotetext{
${ }^{9}$ Can, however, a continuous force be approximated by as a limit of discontinuous impulsive force as the time interval shrinks to zero? This point has often been debated. D.T. Whiteside and E.J. Aiton dismissed its validity (Whiteside 1991, p. 30; Aiton 1972, pp. 103-104). However, an adequate assessment of the situation is not solely contingent on whether we grant Newton's assumption that a continuous force can be approximated as a limit of discontinuous impulsive force: for even if we grant Newton this, his limiting procedure does not prove what he claimed it proved, namely that all centripetal forces produce orbits that lie in a fixed plane, as Pourciau has shown (Pourciau 2003). First of all, Newton could not independently prove the impulse assumption and the claim that areas involved lie on the same plain (the one is required to establish the other and this observations holds for any polygonal approximation) (ibid., esp. the reconstruction of Newton's proof on pp. 277-279). Thus, Newton could only have established that the areas, which bodies made to move in orbits describe radii drawn to an unmoving center of forces and which lie in unmoving planes, are proportional to the times. Furthermore, and even more seriously, Newton's arguments for Proposition I clearly involves impulse motions and limits of impulse motions; however, the conclusion is supposed to be valid for all centripetal forces (impulse and continuous ones). However, Newton's proof of Proposition I can be restored by introducing some additional conditions on the smoothness of a specific curve (see ibid., pp. 291-295).

${ }^{10}$ Proposition II also required the assumption that the resting deflections in the limit motion are directed toward the central point whenever every vertex of every polygonal motion has a resting deflection directed toward the central point (Pourciau 2009, pp. 23-24). A restored proof of Proposition II can be found on ibid., pp. 26-27.

${ }^{11}$ Which states "When bodies are enclosed in a given space, their motions in relation to one another are the same whether the space is at rest or whether it is moving uniformly straight forward without circular motion." (Newton 1999 [1726], p. 423).
} 
cause for Kepler's area rule to hold quam proxime. ${ }^{12}$ In the scholium to Proposition II, Newton stated that:

\begin{abstract}
A body can be urged by a centripetal force compounded of several forces. In this case the meaning of the proposition is that the force which is compounded of all the forces tends towards point $\mathrm{S}$. Further, if some force acts continually along a line perpendicular to the surface described, it will cause the body to deviate from the plane of its motion, but it will neither increase nor decrease the quantity of the surface-area described and is therefore to be ignored in the compounding of forces. (Newton 1999 [1726], pp. 447-448)
\end{abstract}

In Proposition III, Newton argued that "[e]very body that, by a radius drawn to the center of a second body moving in any way whatever, describes about that center areas that are proportional to the times is urged by a force compounded of the centripetal force tending toward that second body and of the whole accelerative force by which that second body is urged [in the same direction along a parallel line (Whiteside (ed.) (1967-1981), VI, p. 126, footnote 77)]" (Newton 1999 [1726], p. 448). Its proof proceeds as follows:

Let the first body be L, and the second T; and (by corol. 6 of the laws ${ }^{13}$ ) if each of the two bodies is urged along parallel lines by a new force that is equal and opposite to the force by which body $\mathrm{T}$ is urged, body $\mathrm{L}$ will continue to describe about $\mathrm{T}$ the same areas as before; but the force by which body $\mathrm{T}$ was urged will now be annulled by an equal and opposite force, and therefore (by law 1) body $\mathrm{T}$, now left to itself, either will be at rest or will move uniformly straight forward; and body $\mathrm{L}$, since the difference of the forces [i.e., the remaining force] is urging it, will continue to describe areas proportional to the times about $\mathrm{T}$. Therefore, the difference of the forces tends (by theor. 2) toward the second body $\mathrm{T}$ as the center. (ibid., p. 448)

Hence, as Newton concluded in Corollary 1, "if a body L, by a radius drawn to another body $\mathrm{T}$, describes areas proportional to the times, and from the total force (whether simple or compounded of several forces according to corol. 2 of the laws) by which body L is urged there is subtracted (according to the same corol. 2 of the laws) the total accelerative force by which body $\mathrm{T}$ is urged, the whole remaining force by which $\mathrm{L}$ is urged will tend toward body T as center" (ibid.). On the basis of Corollary 6 to the laws of motion, Newton indicated that if a body is drawn equally and along parallel lines toward a third body, $S$, the area law would hold exactly (cf. Case 1, Proposition LXVI (ibid., pp. 570-572). Suppose that $S$ is placed at a very large distance from $L$ and $T$. In this case, the force by which $L$ is drawn toward the centre of $S$ can be considered as being nearly parallel to the force by which $T$ is drawn toward $S$. If, furthermore, the force exerted by $S$ is small in comparison to the force by which $L$ is drawn toward $T, L$ will not describe equal areas in equal times exactly but very nearly, for $L$ moves slightly more swiftly near 'conjunction' or 'opposition' and more slowly near the 'quadratures'. Corollaries 2-3 to Proposition III establish that, if the areas are very nearly proportional to the times, the remaining force will tend toward body $T$ very nearly, and conversely. For, if the additional force only slightly accelerates or slows down $L$ 's exact description of equal times in equal periods around $T, L$ will be drawn toward $T$ very nearly, and conversely. Thus, Corollaries 2-3 to Proposition III jointly establish:

\footnotetext{
${ }^{12}$ In fact, when working on De Motu, Newton already realised that the true motions of celestial bodies are immensely complicated and far from being exactly Keplerian. Simultaneously taking in account all causes of planetary motion "exceeds the force of any human mind" (Whiteside (ed.) (1967-1981), VI, p. 78).

${ }^{13}$ Which states: "If bodies are moving in any way whatsoever with respect to one another and are urged by equal accelerative forces along parallel lines, they will all continue to move with respect to one another in the same way as they would if they were not acted by such forces. For those forces, by acting equally (in proportion to the quantities of the bodies to be moved) and along parallel lines, will (by law 2) move all the bodies equally (with respect to velocity), and so will never change their positions and motions with respect to one another (Newton 1999 [1726], p. 423).
} 
The overall centripetal force by which a body is drawn towards a second body is directed to this body very nearly, if and only if, that body describes equal areas in equal times very nearly.

Corollaries 2-3, which are derived from theory, licence the inference of a centripetal force tending quam proxime towards its attractive centre from described areas that are quam proxime proportional to the times. In the scholium following Propositions I-III, Newton concluded:

Since the uniform description of areas indicates the center towards which that force is directed by which a body is most affected and by which it is drawn away from rectilinear motion and kept in orbit, why should we not in what follows use uniform description of areas as a criterion for a center [quidni usurpemus in sequentibus æquabilem arearum descriptionem ut indicem centri] about which all orbital motion takes place in free spaces? (ibid., p. 449)

In Propositions I-III, Newton related phenomena (area rule) to theory (centripetal force): the area rule counted as a measure of the centripetal force. In the way outlined above, Newton argued that a centripetal force is a necessary (Proposition II) and sufficient (Proposition I) cause for the fixed plane property together with the area law. Similarly, in Corollaries 2-3 to Proposition III, i.e. the quam proxime counterparts of Propositions I-II, Newton argued that an overall centripetal force directed very nearly towards a centre is a necessary and sufficient cause of the area law holding very nearly.

The overarching question that Newton was addressing in Propositions I-III can be summarized as follows: What are, given the definitions and the laws of motions, the necessary and sufficient causes of the area rule? As a way of reducing the risk of 'wild speculation', Newton demanded that the causes of orbital motion ought to be derivable from the laws of motion, i.e. from principles that have already shown their merit in natural-philosophical inquiry. Newton, furthermore, demanded that the causes adduced in natural philosophy should not only be shown to entail their effects, but also that these effects are shown to be necessarily produced by those very causes. Put differently, Newton required that there be a systematic dependency between the theoretical parameters and the phenomena they serve to explain. This requirement by itself surpasses a strict hypothetico-deductive methodology: the demand that a centripetal force (or an overall centripetal force directed very nearly toward its centre of force) should be both a necessary and sufficient cause for bodies lying in a fixed plane and describing equal areas in equal times exactly (or very nearly) is to guarantee that such motion is produced by (overall) centripetal forces and (overall) centripetal forces alone. Newton was able to guarantee by the systematic dependency which he had deduced from theory (Corollaries 2-3 to Proposition III) that bodies describing equal areas in equal times very nearly are necessarily produced by an overall centripetal force urging these bodies very nearly towards a centre of force. Instead of introducing ad hoc explanations to account for such deviations, Newton required that deviations, including small deviations, should be accounted for by theory as far as possible.

In the demonstrative part of natural philosophy, Newton remained agnostic about the further explanation and cause of these centripetal forces. Accordingly, he relied on a counterfactual intuition of causation, which did not require Newton to provide details on the further causes producing gravity: if no impressed force acted upon a body, Keplerian motion would not have occurred. Newton's causal explanation of celestial movement involves counterfactual dependence, and more precisely counterfactual-nomological dependence. Note in order to back up causal claims in the counterfactual sense, we need some theoretical background premise that informs us what happens when the putative causal factor is absent. In the case of orbital motion, this information is provided by Newton's first law: if a centripetal does not act upon a body, then this body will remain at rest or conserve its rectilinear inertial motion. This shows that the presence or absence of the centripetal force has 
a noticeable empirical difference. Non-inertial motion can thus be seen as evidence of a real force. In essence, we are comparing the non-uniform and non-rectilinear which bodies actually describe with the uniform rectilinear motions that these bodies would describe if they were not acted upon by an external force. Newton took the statement that gravity exists and is explanatory to mean that he had proved gravity as a primary or proximate cause for the heavenly and terrestrial motions, but that he did not succeed in discovering a further secondary or remote cause for gravity. Nevertheless, an explanation referring exclusively to the primary cause (and neglecting the secondary mechanism - if any - causing it) was fully legitimate to his mind.

\subsection{Newton on Action at a Distance}

Here I shall argue that although Newton rejected Epicurean action at a distance, i.e. although he rejected the view that material bodies by their own nature directly act on each other in vacuo without the mediation of a tertium quid, which was ultimately non-mechanical, he did not think that action at a distance was intrinsically unintelligible. The claim that the sun is the immediate agent-cause of celestial motions was untenable for Newton since he explicitly rejected actio at distans without the mediation of something else which is not material. In a letter to Richard Bentley on 25 February 1692/3, Newton wrote:

It is inconceivable, that inanimate brute Matter, should, without the Mediation of something not material $^{14}$, operate upon, and affect other matter without mutual Contact, as it must be, if Gravitation in the Sense of Epicurus, be essential and inherent in it. And this is the Reason why I desired you not to ascribe innate Gravity to me. That Gravity should be innate, inherent and essential to Matter, so that one body may act upon another at a distance thro' a Vacuum, without the Mediation of any thing else, by and through which their Action and Force may be conveyed from one to another, is to me such an Absurdity, that I believe no Man who has in philosophical Matters a competent Faculty of thinking can ever fall into it. (Cohen 1978, pp. 302-303 [italics added]

Note that with the word "Mediation" Newton is referring to God's interaction, otherwise Newton's clarification which immediately follows that "whether this Agent be material or immaterial, I have left to the Consideration of my Readers" (ibid., p. 303) would be nonsensical (Henry 2007, p. 215). ${ }^{15}$ On the Epicurean account, gravity is an essential and inherent property of particles. In another letter to Richard Bentley, Newton stated clearly:

You sometimes speak of Gravity as essential and inherent to Matter. Pray do not ascribe that Notion to me; for the Cause of Gravity is what I pretend not to know, and therefore would take more Time to consider of it. (Cohen 1978, p. 298)

Such Epicurean view would be untenable for Newton to accept since it would imply that matter itself was self-propelling or self-activating. On the contrary, Newton emphasized that

\footnotetext{
${ }^{14}$ Cf. CUL Add. Ms. 3965, f. $269^{\mathrm{r}}$ [ca. 1693-1694], where Newton wrote: "Nam Planetæ [...] non [...] $\downarrow$ petent se mutuo $\downarrow$ vi $\downarrow$ aliqua $\downarrow$ gravitates neque ullo modo agent in se invicem nisi mediante principio aliquo activo quod utrumque intercedat, et per quod vis ab utroque in alterum propagetur." [italics added].

${ }^{15}$ Given Newton's addition "whether this Agent be material or immaterial", it seems that Newton, during the first years after the publication of the Principia still left open the possibility that gravity was produced by an extremely subtle mechanical ether. However, this would change shortly after 1692/3. In material related to the Classical Scholia (ca. 1694), Newton wrote: "[Hoc medium ex mente veterum non erat corporeum cum corpora universa ex essentia sua gravia esse dicerent, atque atomos $\downarrow$ ipsos vi æterna $\downarrow$ naturæ suæ absque aliorum corporum impulse per spatia vacua in terram cadere.]" (CUL Add. Ms. 3965, f. 269 ${ }^{\mathrm{r}}$ ). This change was rendered explicit in the General Scholium to second edition of the Principia. The ethers Newton introduced in The Opticks (and related manuscript material) were clearly non-mechanical: they required non-material interaction of micro-level forces (see infra).
} 
matter itself is utterly passive and that it requires the activity of certain non-mechanical "Active Principles". Bodies are passive and are moved by active principles, i.e. immaterial agents: "[f]or we meet very little Motion in the World, besides what is owing to these active Principles" (Newton 1979 [1730], p. 399). In line with his metaphysical and theological outlook, he saw his theory as providing room for non-mechanical forces in nature and bringing such forces to the fore was central to Newton's Principia project. ${ }^{16}$ In his preface of the Principia Newton declared that the basic difficulty of natural philosophy is "to discover the forces of nature from the phenomena of motions and then to demonstrate the other phenomena from these forces" (ibid., p. 382). In the General Scholium (1713) Newton explicitly noted that "all these regular motions [i.e. celestial motions] do not have their origin in mechanical causes, since comets go freely in very eccentric orbits and into all parts of the heavens" (ibid., p. 940). Newton thus endorsed the view that non-material agents mediated the gravitational attraction of material bodies in vacuo (ibid., p. 339, pp. 310-370). John Henry adequately notes that the ethers Newton introduced to account to explain gravitation were not mechanical since they "consisted of particles held apart from one another, and from particles to other matter, by repulsive forces operating between them" (Henry 1994, p. 123) ${ }^{17}$ and that "the aether theories were not intended to be a way of avoiding actions at a distance" (ibid., p. 135) ${ }^{18}$. These points are indeed well taken. ${ }^{19}$

The subtle answer to the conundrum of action at a distance is the following: Newton denied that matter could gravitationally act at a distance according to its own nature (because this would imply that matter would be innately self-acting, an option incompatible to Newton's metaphysical and theological views); however, Newton endorsed action at a distance for the secondary mechanism producing gravity, because he postulated an "elastick ether" consisting of repellent particles acting at a distance (Newton 1999 [1726], p. 699). In a nutshell: for metaphysical and theological reasons Newton rejected action at a distance at a macro-level but accepted it at a micro-level. Newton thus had no a priori objections against actio in distans. ${ }^{20}$

\section{Newton's Argument for Universal Gravitation}

In this section, I bring to the fore the diversity of understanding provided by Newton's argument for universal gravitation. I shall do so by focussing on the first Propositions (I-VIII) from Book III as in the third edition of the Principia mathematica (1727). Correspondingly, I shall deal with the analytic part of Newton's argument for universal gravitation where the

\footnotetext{
${ }^{16}$ Note that De Regt and Dieks discuss Newton's theory of universal gravitation but - quite ironically mentioned that apparently "Newton had difficulty with the metaphysics now associated with Newtonian theory: there was no room for actio in distans in the corpuscularist worldview to which he adhered" and that he "did not accept it as a tool for scientific understanding” (de Regt \& Dieks 2005, p. 161).

${ }^{17}$ Newton's account of gravitation as being produced by "the elastick force" of mutually repellent small particles occurs in Query 21 (Newton 1979 [1730], pp. 350-352).

${ }^{18}$ This observation is entirely correct, for if Newton thought otherwise we would be lead to accept the conclusion that Newton tried to explain action at a distance at the macro-level away by reintroducing it at the micro-level.

${ }^{19}$ In Janiak 2007, Janiak did not refer to Henry's work. He does so in Janiak 2008, p. 53, footnote 53. There Henry's views are quickly dismissed on the basis of an excerpt wherein Henry (incorrectly) wrote that gravity is "a superadded inherent property" (Henry 1994, p. 141; note however, that in Henry, 2007 this mistake is corrected). In any case, Henry's slip should not detract us from the important points he made: that the ether theories did not originate in Newton's dissatisfaction with action at a distance per se, and that Newton accepted action at a distance in his optical work and in his work on the cause of gravity. In his subsequent discussion (Janiak 2008, pp. 53-65), Janiak does not consider these two points.

${ }^{20}$ This conclusion was also reached in McMullin 1978, p. 144, footnote 13 and p. 151, footnote 210.
} 
statement of universal gravitation is derived. The synthetic part stretches out to the very end of Book III (Ducheyne 2005b).

\subsection{Propositions I-II: The Inference of Inverse-square Centripetal Forces Acting on the Primary and Secondary Planets}

Propositions I and II of Book III underwent no significant changes in any of the Principia's editions. In Proposition I, Newton inferred from Phenomenon ${ }^{21} \mathrm{I}$, which states that "[a] the circumjovial planets, by radii drawn to the center of Jupiter, describe areas proportional to the times, and [b] their periodic times - the fixed stars being at rest ${ }^{22}$ - are as the $3 / 2$ powers of their distances from that center" (Newton 1999 [1726], p. 797), that "[a'] [t]he forces by which the circumjovial planets are continually drawn away from rectilinear motions and are maintained in their respective orbits are directed to the center of Jupiter and $\left[\mathrm{b}^{\prime}\right]$ are inversely as the squares of the distances of their places from that center" (ibid., p. 802) by Proposition II, Book I - in case Kepler's area law is taken exactly - or Proposition III, Book I - in case Kepler's area law is taken quam proxime - and Corollary 6 to Proposition IV $^{23}$ of Book I which takes the harmonic law to hold exactly, respectively. The same procedure can be applied for the circumsaturnian planets by Phenomenon II and the same propositions of Book I. ${ }^{24}$

In Proposition II, Newton inferred from Phenomenon V, which states that "[a] [t]he primary planets, by radii drawn to the earth, describe areas in no way proportional to the times ${ }^{25}$ but, by radii drawn to the sun, traverse areas proportional to the times" (Newton, 1999 [1726], p. 801), and Phenomenon IV, which states that "[b] [t] he periodic times of the primary planets and of either the sun about the earth or the earth about the sun ${ }^{26}$ - the fixed stars being at rest - are as the 3/2 powers of their mean distances from the sun" (ibid., p. 800), that "[a'] [t] he forces by which the primary planets are continually drawn away from rectilinear motions and are maintained in their respective orbits are directed to the sun and $\left[\mathrm{b}^{\prime}\right]$ are inversely as the squares of their distances from its center" (ibid., p. 802), by Proposition II of Book I which takes the area law to hold exactly, and Corollary 6 to Proposition IV, which takes the harmonic law to hold exactly, respectively. Moreover, in the case of the primary planets the inverse square law is proved "with the greatest exactness from the fact that the aphelia are at rest" (ibid.), since the slightest departure ("aberratio") from an inverse square law would entail motion in the aphelia (by Book I, Proposition $\mathrm{XLV}^{27}$ ).

\subsection{Propositions III-IV: The Inference of an Inverse-square Centripetal Force Acting on the Moon}

\footnotetext{
${ }^{21}$ Newton's "phenomena" are inductive generalizations based on a large number of singular astronomical observations and their complex mathematical processing. Here I shall not further discuss how these astronomical observations were obtained. Instead I refer the reader to Densmore 1995, pp. 242-282.

${ }^{22}$ I.e., here, as in the rest of the Principia, Newton considered relative motions.

${ }^{23}$ For the secondary planets Newton's application of Corollary 6 is no surprise, since he assumes that the orbits of the circumjovial planets, e.g., do "not differ sensibly from circles concentric with Jupiter" (Newton 1999 [1726], p. 797). Newton presupposes a circular approximation here.

${ }^{24}$ While Newton came to accept the empirical validity of Kepler's harmonic rule from quite early on, it was only shortly before the composition of De motu that Newton came to accept the area rule when John Flamsteed's astronomical observations indicated a fairly accurate confirmation of it (ca. 1684). See Whiteside 1964 and 1970 , Russell 1964, Thoren 1974 and Wilson 1974 for further discussion.

${ }^{25}$ Here Newton rejected geocentrism.

${ }^{26}$ At this point, Newton leaves open the possibility of the Tychonic theory. It is only in Proposition XII of Book III that Newton established that the sun is the common centre of gravity of all planets (Newton 1999 [1726], p. 817).

${ }^{27}$ On Newton's apsidal precession theorem, see furthermore Valluri, Wilson \& Harper 1997.
} 
In Proposition III Newton showed that "[t]he force by which the moon is maintained in its orbit is directed toward the earth and is inversely as the square of the distance of its places from the center of the earth" (ibid.). The first part of this proposition is established by Phenomenon VI ${ }^{28}$, which states that the moon by a radius drawn to the centre of the earth describes areas proportional to the times (ibid., p. 801), and Proposition II or Proposition III of Book I - the area law for the moon holds exactly only in the absense of the sun's disturbing gravitational force of the sun on the moon. Because the moon is a solitary satellite, Newton cannot use the route via Corollary 6 to Proposition IV. The second part of Proposition III, however, follows from the very slow motion of the moon's apogee (which is caused by the sun's disturbing force): "[f]or that motion, which in each revolution is only three degrees and three minutes forward [or in consequentia, i.e., in an easterly direction] can be ignored." (ibid., pp. 802803). ${ }^{29}$ From Corollary 1 to Proposition XLV, Book I, it follows that the centripetal force by which the moon is drawn to the earth is proportional to the $n$-th power of the distance, where $n$ equals $\left(360 /\left(360+p^{\circ}\right)\right)^{2}-3$ and $p^{\circ}$ is the moon's apsidal motion in degrees. In case of a $3^{\circ} 3^{\prime}$ apsidal motion, $n$ equals $\left(360 /\left(360+3^{\circ} 3^{\prime}\right)\right)^{2}-3$, i.e. the centripetal force by which the moon is drawn to the earth is proportional to the ca. $-2,01673$ power of the distance (or, in Newton's phrasing, approximately as the inverse $2_{4 / 243}$ power $^{30}$ of the distance) (ibid., p. 803). Thus: "the proportion of the force to the distance is inversely as a little greater than the second power of the distance, but is $59_{3 / 4}$ times closer to the square than to the cube" (ibid.). ${ }^{31}$ In Corollary 2 to Proposition XLV, Book I, it is shown that, if the centripetal force by which a body (the moon) revolves in an ellipse varies inversely to the square of the distance from the centre of another body (the earth), the motion of the apsides (in degrees) that arises from the extraneous centripetal force of a third body (the sun) can be determined as follows - on the assumption that the extraneous force is 375.35 times less $^{32}$ than the inverse-square centripetal force by which the body describes an ellipse: $p^{\circ}=180^{\circ} \sqrt{ }[(1-(1 / 357.45)) /(1-4(1 / 357.45))] \approx$ $180.7623^{\circ}$ (i.e. $\approx 180^{\circ} 45^{\prime} 44^{\prime \prime}$ ) (ibid., p. 545, p. 803). ${ }^{33}$ Since the moon when departing from the upper apsis will arrive at the lower apsis by an angular motion of $180^{\circ} 45^{\prime} 44^{\prime \prime}$, it follows that in each revolution the upper apsis will move forward through $1^{\circ} 31^{\prime} 28^{\prime \prime}$. Since Newton furthermore assumed that "[t]he [advance of the] apsis of the moon is about twice as swift" (ibid., p. 545) ${ }^{34}$, it follows that the extraneous force of the sun is to the centripetal of the moon as roughly $2 / 357.45$ or as $1 / 178_{29 / 40}$ and that in each revolution the upper apsis will move forward through $3^{\circ} 2^{\prime} 56^{\prime \prime}$, a value that agreed nicely with the $3^{\circ} 3^{\prime}$ derived from astronomical observation (ibid. p. 803). The latter step contained a serious lacuna, however, for the

\footnotetext{
${ }^{28}$ In commenting on Proposition VI, Newton noted: "Actually, the motion of the moon is somewhat perturbed by the force of the sun, but in these phenomena I pay no attention to minute errors that are neglegible." (Newton 1999 [1726], p. 801).

${ }^{29}$ A translation more close to the original is: "which in each revolution is only three degrees and three minutes in consequentia [i.e., in an easterly direction forward]".

${ }^{30}$ This is the value Newton had calculated in Corollary 1 to Proposition XLV (Newton 1999 [1726], pp. 802-803, p. 544).

31 This force differs 4/243 from the inverse-square proportion and 239/243 from the inverse-cube proportion. By dividing the difference from the cube proportion, 239/243, by the difference from the inverse-square proportion, $4 / 243$, we arrive at $59_{3 / 4}$.

${ }^{32}$ Newton, first of all, decomposed the sun's perturbing force on the moon into a radial and a transradial component. Given the mathematical properties of a three-body system based on Proposition LXVI of Book I which takes the moon's orbit to be circular - and by an application of Corollary 17 to Proposition LXVI, Book I (cf. Proposition XXV, Book III (Newton 1999 [1726], p. 840)), Newton calculated the average value of the radial component of the sun's perturbing force that draws the moon away from the earth - here he abstracted from the sun's transversal component - is to the acceleration of the moon to the earth as $1 / 2\left(\mathrm{~T}_{\mathrm{M}} / \mathrm{T}_{\mathrm{E}}\right)^{2}$, i.e. as $1 / 2\left(\left(27^{\mathrm{d}} 7^{\mathrm{h}} 43^{\mathrm{m}}=39,343 \text { minutes }\right) /\left(365^{\mathrm{d}} 6^{\mathrm{h}} 9^{\mathrm{m}}=525,969 \text { minutes }\right)\right)^{2}$, which yields a ratio of ca. 1 to 357.45 (Wilson 1989 , p. 264).

${ }^{33}$ The computation based on Corollary 2 to Proposition XLV, Book I, was added in the second edition.

${ }^{34}$ The line "Apsis Lunæ est duplo velocior circiter." was added in the third edition.
} 
assumption that the moon's apsis moves twice as fast was not derived from theory (Whiteside 1976, p. 320; Whiteside (ed.) (1967-1981), vol. VI, pp. 508-510, footnote 1, and pp. 518-519, footnote 26; Aoki 1992, p. 151, footnote 12; Wilson 2000, pp. 155-172). Initially, Newton seemed to think that the sun's transverse radial component could account for the doubling of the motion of the moon's apsis; later, for reasons unknown to us, he abandoned this explanation and perhaps even considered non-gravitational to account for the other half of the moon's apsidal motion factors (e.g. the earth's magnetic force) (Smith 1999, p. 261).

The inverse-square character of the centripetal force which draws the moon to the earth is, furthermore, established in Proposition IV, which contains Newton's famous moon test. The moon test sets out to prove that the earth's gravity extends to the moon and varies inversely as the square of the distance from the centre of the earth. Required for the computation of the moon test are two basic elements: the mean distance of the moon from the earth and the moon's period, i.e. 27 days, 7 hours, 43 minutes (or 39,343 minutes) ${ }^{35}$. For the mean moonearth distance different values were available at the time. Newton noted that according to (Ptolemy ${ }^{36}$ and) most astronomers the mean distance of the moon from the earth is 59 earth semi-diameters (all editions), according to Vendelin (and Huygens ${ }^{37}$ ) 60 (all editions), according to Copernicus $60_{1 / 3}$ (all editions), according to Kircher $62_{1 / 2}$ (first edition only), according to Tycho $56_{1 / 2}{ }^{38}$ (all editions), and according to Street $60_{2 / 5}$ (third edition). In all editions, Newton took 60 terrestrial semi-diameters as the value for the mean moon-earth distance in the moon test (Newton 1999 [1726], p. 804). ${ }^{39}$ Suppose that the sun is at rest and that the moon is deprived of all its motion and set to fall towards the earth with all that force by which it is normally kept in orbit, then the moon will fall a distance of $15_{1 / 12}$ Paris feet ${ }^{40}(\approx$ 15,083 Paris feet) or, as he added in the third edition, "more exactly 15 feet, 1 inch, and $1_{4 / 9}$ lines" (ibid.) ${ }^{41}(\approx 15.093$ Paris feet) in one minute (by Corollary 9 to Proposition IV, Book I, or Proposition XXXVI, Book I).

From what is given, the period of the moon is 39,343 minutes $\left(\mathrm{T}_{\mathrm{M}}=39,343^{\prime}\right)$ and the circumference of the earth is 126,249,600 Paris feet $\left(C_{E}=123,249,600\right.$ Paris feet $)$. The earth's diameter $\left(D_{E}\right)$ can be determined as follows, $D_{E}=C_{E} / \pi$ or $D_{E}=(123,249,600$ Paris feet $) / \pi \approx$ $39,231,566.1481$. Since the circumference of the moon equals 60 earth circumferences, $C_{M}=$

\footnotetext{
${ }^{35}$ This value remained unchanged in all editions.

${ }^{36}$ Ptolemy's name was added in the third edition.

${ }^{37}$ Huygens' name was added in the third edition.

${ }^{38}$ With respect to Tycho's value, Newton observes: "But Tycho and all those who follow his table of refractions, by making the refractions of the sun and moon (entirely contrary to the nature of light) be greater than those of the fixed stars - in fact greater by about four or five minutes - have increased the parallax of the moon by that many minutes, that is, by about a twelfth or fifteenth of the whole parallax. Let that error by corrected, and the distance will come to be roughly $60_{1 / 2}$ terrestrial semidiameter, close to the value that has been assigned by others" (Newton 1999 [1726], pp. 803-804). In the first edition Newton corrected Tycho's value as to result in 61 terrestrial semi-diameters; in the second edition he corrected Tycho's value as to result in $60_{1 / 2}$ terrestrial semidiameters.

${ }^{39}$ The average of the five values Newton provided in the third edition is ca. 60,047. In the first edition, the average is ca. 60,567 terrestrial semi-diameters. In the second edition, it is ca. 59,958 terrestrial semi-diameters.

${ }^{40}$ One Paris foot equals 1.066 English feet (Densmore 1995, p. 299).

${ }^{41}$ In the first edition Newton wrote $15_{1 / 12}$ Paris feet tout court; in the second edition he wrote "pedum Parisiensium 15 $1 / 12$ circiter". It is worth mentioning Shinko Aoki's conclusion on the accuracy of the moon test: "Newton believed he had shown the inverse-square law to be more exactly verified than was in fact the case. If in the Moon-test an accuracy of one part in 6000 was [implicitly] required, in Newton's opinion, to provide an empirical basis for the structure of the Principia, then Newton failed in his effort, because he mistook the calculations necessary for this purpose. He would have done better to remain content with the accuracy obtained in the first edition of Proposition IV of Book III; this was reasonably given because the observational data Newton used were poorly determined. It would not then have been necessary to consider sophisticated correction factors in verifying the inverse-square law; these were superfluous, or it was at least premature to take them into account." (Aoki 1992, p. 169).
} 
$60 \times 123,249,600$ Paris feet $=7,394,976,000$ Paris feet. As $D_{M}=C_{M} / \pi, D_{M}=(7,394,976,000$ Paris feet) $/ \pi \approx 2,353,893,968.8919$. As the moon in orbit travels $7,394,976,000$ Paris feet in a period of 39,343 minutes, it follows that it will travel through an orbital distance of 187,961.6704 Paris feet in one minute. Since from Corollary 9 to Proposition IV of Book I, "the arc which a body, in revolving uniformly in a circle with a given centripetal force, describes in any time is a mean proportional between the diameter of the circle and the distance through which the body would fall under the action of the same given force and in the same time" (ibid., p. 451), it follows that the distance the moon would traverse in a one minute fall to the earth equals: (the distance the moon traverses in orbit in a one minute period) ${ }^{2} / \mathrm{D}_{\mathrm{M}}$, i.e. $(187,961.6704 \text { Paris feet })^{2} / 2,353,893,968.8919$ Paris feet $\approx 15.009$ Paris feet. $^{42}$

However, this is not yet the final value Newton obtained. Recall that Newton's initial approximation abstracts from the influence of the sun. Therefore, Newton corrects the above result with a factor that takes into account the moon's acceleration toward the sun. The obtained 15.009 Paris feet should be corrected by $1 / 178.725$ of that value (ibid., p. 803, p. 840). The corrected value $\left(r^{\prime}\right)$ is then established as follows: $r^{\prime}=(15.009$ Paris feet $\times 1 / 178.725)+$ 15.009 Paris feet $\approx 15.093$ Paris feet. ${ }^{43}$ Accordingly, "since in approaching the earth that force is increased as the inverse square of the distance, and so at the surface of the earth is $60 \times 60^{44}$ times greater than at the moon, it follows that a body falling with that force, in our regions, ought in the space of one minute to describe $60 \times 60 \times 15_{1 / 12}$ Paris feet, or more exactly 15 feet, 1 inch, and $1_{4 / 9}$ lines ${ }^{45}[\approx 15.093$ Paris feet]" (ibid., p. 804). Hence, in a period of one second a body at the surface of the earth falls 15.093 Paris feet ${ }^{46}$ Bodies falling near the earth traverse almost exactly the same distance in an equal amount of time. Huygens had measured that swinging bodies near the surface of the earth traverse 15 Paris feet, 1 inch, $1_{7 / 9}$ lines or 15.0956 Paris feet in one second. ${ }^{47}$ Since the value calculated from the moon test and Huygens' value are very close, and since the moon would fall in the same direction as terrestrial bodies in free fall, Newton concluded:

And therefore that force by which the moon is kept in orbit, in descending from the moon's orbit to the surface of the earth, comes out equal to the force of gravity here on earth [æqualis evadit vi gravitatis apud nos], and so (by rules 1 and 2$)^{48}$ is that very force which we generally call gravity [est illa ipsa vis quam nos gravitatem dicere solemus]. (ibid.)

In other words: Newton, in his moon test, and Huygens, in his pendulum experiments, had measured the same force. As Howard Stein has shown, Newton's inductive conclusion should be read as Newton establishing that terrestrial bodies and the moon are both subject to the accelerative force of the earth which extends in all directions (Stein 1970, pp. 267-268). ${ }^{49} \mathrm{In}$ the scholium added to Proposition IV in third edition of the Principia, Newton noted that "the proof of this proposition can be treated more fully [fusius explicari potest]" by means of a thought-experiment (Newton 1999 [1726], p. 805). Suppose that several moons revolve around

\footnotetext{
${ }^{42}$ Here I have calculated this value from the route Newton suggested via Corollary 9 to Proposition IV of Book I. For the route via Proposition 36 of Book I using the versed sine, see Spencer 2004, pp. 779-780.

${ }^{43}$ On the actual value given by Huygens and its derivation, see Aoki 1996, p. 394.

${ }^{44}$ In opting for 60 earth semi-diameters as the moon-earth distance Newton made the computation to the best advantage as to the numbers in terms of accuracy (cf. Westfall 1973, p. 755). Nevertheless, the correlation Newton established was quite strong: William L. Harper has correctly indicated that if we neglect from Newton's 1/178.25 correction and take each of the lunar distances cited in the third edition of the Principia separately, Huygens' value is still well within the error bounds of 14.612-15.47 Paris feet (Harper 2002a, p. 182). 451 "line" is a twelfth of an inch.

${ }^{46}$ Since $\left(60 \times 60 \times 15_{1 / 12}\right.$ Paris feet $) /(60 \mathrm{~s})^{2}=15_{1 / 12}$ Paris feet $/(1 \mathrm{~s})^{2}$.

${ }^{47}$ In the first and second edition Newton gave $15_{1 / 12}$ tout court Paris feet for Huygens' value.

${ }^{48}$ On the regulae philosophandi see 4.3 .

${ }^{49}$ The same point holds for the accelerative force of the primary planets on their satellites, the accelerative force of the sun, and the accelerative force of all bodies universally.
} 
the earth. Their periodic times will "by the argument of induction [per argumentum inductionis]" obey Kepler's law and therefore their centripetal forces will vary inversely as the square of the distance. Suppose further that the lowest of them would nearly touch the highest mountains. It follows, by the previous computation, that the gravities of this moon will be nearly equal to the gravities on the tops of the mountains. Now, if the force by which the lowest moon descends was different from gravity and the little moon was also heavy toward the earth, then it would - contrary to experience - either descend twice as fast by both forces acting together or not at all. Therefore, Newton repeated his conclusion:

Since both forces - namely those of heavy bodies and those of the moons - are directed toward the center of the earth and similar to each other and equal [similes et æquales], they will (by rules 1 and 2) have the same cause [eandem habebunt causam]. (ibid.)

\subsection{Proposition V: From Centripetal Force to "Gravity"}

Proposition V established that the circumjovial planets, the circumsaturnian planets and the primary planets gravitate toward Jupiter, Saturn and the sun, respectively, and are "always drawn back from rectilinear motions and kept in curvilinear orbits [retrahi semper a motibus rectilineis, \& in orbibus curvilineis retineri]" (ibid.). The revolutions of the circumjovial planets about Jupiter, the revolutions of the circumsaturnian planets about Saturn, and the revolutions of the primary planets about the sun are phenomena of the same kind as the revolution of the moon about the earth and, therefore, by Rule II "depend on causes of the same kind [a causis ejusdem generis dependent], especially since it has been proved that the forces on which those revolutions depend are directed toward the centers of Jupiter, Saturn, and the sun, and decrease according to the same ratio and law (in receding from Jupiter, Saturn, and the sun) as the force of gravity (in receding from the earth)" (ibid., p. 806).

Since the primary and secondary planets are bodies of the same kind as Jupiter and Saturn and since, by Law III, every attraction is mutual, Jupiter and Saturn will in their turn gravitate toward their satellites, the earth will gravitate toward the moon, and the sun will gravitate toward the primary planets (Corollary $1^{50}$ ). In Corollary 2, Newton established that the gravity that is directed towards every planet is inversely as the square of the distance of places from the centre of the planet. ${ }^{51}$ In Corollary 3, which was added in the second edition of the Principia, added "[a]nd hence Jupiter and Saturn near conjunction, by attracting each other, sensibly ${ }^{52}$ perturb each other's motions, the sun perturbs the lunar motions, and the sun and moon perturb our sea, as will be explained in what follows [ut in sequentibus explicabitur]" (ibid., p. 806) ${ }^{53}$ In the scholium following Proposition V, which was added in the third edition of the Principia, Newton wrote:

\footnotetext{
Hitherto we have called "centripetal" that force by which celestial bodies are kept in their orbits. It is now established that this force is gravity, and therefore we shall call it gravity from now on. For the cause of the centripetal force by which the moon is kept in orbit ought to be extended [extendi debet] to all the planets, by rules 1,2 , and $4^{54}$. (ibid., p. 806)
}

\footnotetext{
${ }^{50}$ Corollary 1 was slightly different in the first edition. The difference is, however, not relevant to our present discussion.

${ }^{51}$ Corollary 2 was identical in all editions.

${ }^{52}$ I.B. Cohen pointed out that the effect Newton was looking for was too small to be detected with the instruments available at the time (Newton 1999 [1726], p. 211).

${ }_{53}$ Corollary 3 was added in the second edition and remained unchanged in the third.

${ }^{54}$ Rule IV was added in the third edition of the Principia: "In experimental philosophy, propositions gathered from phenomena by induction should be considered [haberi debent] either exactly or very nearly true notwithstanding any contrary hypotheses, until yet other phenomena make such propositions either more exact or liable to exceptions [accuratiores reddantur aut exceptionibus obnoxiæ]. This rule should be followed so that arguments based on induction may not be nullified [tollatur] by hypotheses." (Newton 1999 [1726], p. 796).
} 
Newton's theory of universal gravitation as developed in Book III was not only established by means of the physico-mathematical machinery Newton had developed in Book I, but also by means of a set of methodological rules ${ }^{55}$ which were to justify and underwrite the inductive generalizations made in Book III. While Propositions I-III, Book I, offered criteria for the inference of instances of centripetal forces, the rules of philosophizing regulated further inductive generalisations - once different instances of centripetal forces were inferred and once further empirical data was provided.

RULE I.

No more causes of natural things should be admitted than are both true and sufficient to explain their phenomena.

As the philosophers say: Nature does nothing in vain, and more causes are in vain when fewer suffice. For nature is simple and does not indulge in the luxury of superfluous causes. (ibid., p. $794)^{56}$

This rule prima facie expresses the idea of causal minimalism: the number of causes in natural phenomena should not be inflated beyond necessity because nature operates economically. Upon closer consideration, and more importantly, Newton also provides two desiderata that a proper cause in natural philosophy should meet: a cause should not merely be explanatory, it should also be true. Put differently, a true cause should not merely explain its effect; it should also be shown that its observable effect necessarily follows from this very cause. Once this is established, then, when its corresponding effect is observed, the cause can be inferred to exist. On this reading, Rule I then asserts that causes shown to be necessary and sufficient of their effects are to be kept minimal.

Rule II is basically a corollary to Rule I (cf. “ideoque”):

RULE II.

Therefore, the causes assigned to natural effects of the same kind must be, so far as possible, the same.

Examples are the cause of respiration in man and beast, or of the falling of stones in Europe and America, or of the light of a kitchen fire and the sun, or of the reflection of light on our earth and planets. (ibid., p. 795)

The formulation of Rule II underwent some significant change: whereas Newton originally wrote "Ideoque effectuum naturalium ejusdem generis eadem sunt causa.", in the second and third edition he was more careful: "Ideoque effectuum naturalium ejusdem generis eadem assignandae sunt causa, quatenus fieri potest." (Koyré e.a. (1972), vol. II, pp. 550-551 [underscores added]). Rule II therefore licenses the identification of instances of causes of the same kind which have been shown to be true and sufficient to explain their phenomena. Obviously, Rule II requires a criterion to decide when causes are "of the same kind", which Newton does not explicitly give. However, it can be reconstructed from Newton's actual applications of Rule II.

Let us now go back for a moment to a crucial step in Newton's argument for universal gravitation: the application of Law III in Corollary 1 to Proposition V. Newton had illustrated the law of action-reaction by means of two bodies which were interposed by a third body. The question now was whether Law III could be legitimately applied to two gravitationally interacting celestial bodies. This concern was raised by Roger Cotes, who in a letter to Newton in $1712 / 13$, wrote:

\footnotetext{
${ }^{55}$ See furthermore: Cohen 1966; Koyré 1965, chapter 6.

${ }^{56}$ In the second edition, Newton changed "sufficiunt" into "sufficiant" and added the sentence "Dicunt utique philosophi (...) potest per pauciora.” (Koyré, e.a. 1972, vol. II, pp. 550-551).
} 
But in the first Corollary of the 5th [proposition of Book III] I meet with a difficulty, it lyes in these words Et cum Attractio omnis mutua sit I am persuaded they are true when the Attraction may properly be so call'd, otherwise they may be false. You will understand my meaning by an Example. Suppose two Globes $A \& B$ placed at a distance from each other upon a Table, \& that whilst $A$ remains at rest $B$ is moved towards it by an invisible Hand. A by-stander who observes this motion but not the cause of it, will say that $B$ does certainly tend to the centre of $A, \&$ thereupon he may call the force of the invisible Hand the Centripetal force of $B$, or the Attraction of $A$ since ye effect appears the same as if it did truly proceed from a proper $\&$ real Attraction of $A$. But then I think he cannot by virtue of the Axiom [Attractio omnis mutua est] conclude contrary to his Sense and Observation, that the Globe $A$ does also move towards Globe $B \&$ will meet it at the common centre of Gravity of both Bodies. (...) For 'till this Objection be cleared I would not undertake to answer any one who should assert You do Hypothesim fingere I think You seem tacitly to make this Supposition that he Attractive force resides in the Central Body. (Cotes to Newton, 18 March 1712/13, Turnbull, e.a. (eds.) (1959-1977), vol. V, p. 392)

\title{
According to Howard Stein's diagnosis Newton was tacitly introducing a hypothesis in Corollary 1 to Proposition $\mathrm{V}^{57}$ :
}

\begin{abstract}
The third law of motion does not tell us that whenever one body is urged by a force directed towards a second, the second body experiences an equal force towards the first; it tells us, rather, that whenever one body is acted upon by a second, the second body is subject to a force of equal magnitude and opposite direction. Therefore - putting the point in proper generality - what we may legitimately conclude, from the proposition that each body is a center of gravitational force acting upon all bodies, is that for each body $B$ there must be some body (or system of bodies) $B^{\prime}$ which, exerting this force on $B$, is subject to the required equal and opposite reaction. (Stein 1990, p. 217 [italics in original])
\end{abstract}

Cotes' challenge to Newton consisted in raising the issue whether Newton had actually shown that the gravitational counterforce resides in the attracted body. Newton's formal response to Cotes' worry is often quoted. ${ }^{58}$ It is, however, the draft version of this letter, which varies significantly from the letter Cotes received, that sheds more light on Newton's tackle of the matter. The significance of the draft lies in the fact that it makes it clear that Newton did not consider the application as a straightforward deduction from Law III, but rather as an inductive generalization guided by his rules of philosophy:

And when you come at the difficulty you mention in the first Corollary of the $5^{\mathrm{t}}$ Proposition of the third Book, wch lies in these words Et cum Attractio omnis mutua sit: the Objection you mention may be proposed \& answered in this manner. 1 That it is but an Hypothesis not founded upon any one Observation. 2 That it is attended wth the absurd consequence described ${ }^{59}$ p. 22 , namely that a body attracted by another body without mutually attracting it would go to the other body and drive

\footnotetext{
${ }^{57}$ This has some truth to it, for Newton obviously not measure the equality of the active gravitational mass and the passive gravitational mass, a point forcefully made in Harper 2002b, pp. 92-94.

${ }^{58}$ For the reader's convenience I provide the relevant extract from the letter that Cotes received: "[T]he Difficulty you mention wch lies in these words [Et cum Attractio omnis mutua sit] is removed by considering that as in Geometry the word Hypothesis is not taken in so large a sense as to include Axiomes \& Postulates, so in experimental Philosophy it is not to be taken in so large a sense as to include the first Principles or Axiomes wch I call the laws of motion. These Principles are deduced from Phænomena \& made general by Induction: wch is the highest evidence that a Proposition can have in this philosophy. And the word Hypothesis is here used by me to signify only such a Proposition as is not a Phænomena nor deduced from any Phænomena but assumed or supposed wthout experimental proof. Now the mutual \& mutually equal attraction of bodies is a branch of the third Law of motion \& how this branch is deduced from Phænomena you may see in the end of the Corollaries of ye Laws of Motion, pag. 22. If a body attracts another body contiguous to it \& is not mutually attracted by the other: the attracted body will drive the other before it \& both will go away together wth an accelerated motion in infinitum, as it were by a self moving principle, contrary to ye first law of motion, whereas there is no such phænomena in all nature." (Newton to Cotes, 28 March 1713, Turnbull, e.a. (eds.) (1959-1977), vol. V, pp. 396399, pp. 396-397).

${ }^{59}$ In the original "described" is preceded by "attende" (CUL Add. Ms. 3984.14, f. $1^{\mathrm{r}}$ ).
} 
it away before it with an accelerated motion in infinitum, contrary to ye first law of Motion. And such an absurd Hypothesis wch would disturb all nature, is not to be admitted in opposition to the first \& third Laws of motion wch are grownded upon Phænomena. For that all attraction is mutual $\&$ mutually equal follows from both those laws. One may suppose that bodies may by an unknown power be perpetually accelerated \& so reject the impenetrability of matter. One may suppose that God can create a penetrable body \& so reject the impenetrability of matter. But to admitt of such Hypotheses in opposition to rational ${ }^{60}$ Propositions founded upon Phænomena by Induction is to destroy all arguments taken from Phænomena by Induction \& all Principles founded upon such arguments. And therefore as I regard not Hypotheses in explaining the Phenomena of nature so I regard them not in opposition to arguments founded upon Phænomena by Induction or to Principles setled upun such arguments. In arguing for any Principle or Proposition from Phænomena by Induction, Hypotheses are not to be considered. The Argument holds good till some Phænomena can be produced against it. This Argument holds good by the third Rule of philosophizing. And if we break that Rule, we cannot affirm any one general law of nature: we cannot so much as affirm that all matter is impenetrable. Experimental Philosophy reduces Phænomena to general Rules \& looks upon the Rules to be general when they hold generally in Phænomena. It is not enough to object that a contrary phænomenon may happen but to make a legitimate objection, a contrary phenomenon must be actually produced. Hypothetical Philosophy consists in imaginary explications of things \& imaginary arguments for or against such explications, or against arguments of Experimental Philosophers founded upon Induction. The first sort Philosophy is followed by me, the latter too much by Cartes, Leibnitz \& some others. And the mutual equality of Attraction (wch is a branch of the third Law of motion) is backt by this further argument that is if the attraction between two bodies was not mutual and mutually equall they would not stay in rerum natura. The body wch is most strongly attracted would go to the other \& press upon it, \& by the excess of its pressure both would go away together with a motion accelerated in infinitum. (...) Thus the Objection wch you mention is not only a Hypothesis \& on that account to be excluded [from] experimental Philosophy, but also introduces a principle of self motion into bodies wch would disturbe the whole frame of nature, $\&$ in the general opinion of mankind is as remote from the nature of matter as impenetrability [read: penetrability] is recconed to be. Experimental philosophy argues only from phænomena, draws general conclusions from the consent of phænomena, \& looks upon the conclusion as general when ye consent is general without exception, tho the generality cannot be demonstrated a priori. In Mathematicks all Propositions not demonstrated mathematically are Hypotheses, but some are admitted in as Principles under the name of Axioms or Postulates wthout being called Hypothesis. So in experimental Philosophy its proper to distinguish Propositions into Principles, Propositions \& Hypotheses, calling those Propositions wch are deduced from Phænomena by proper Arguments \& made general by Induction (the best way of arguing in Philosophy for a general Proposition) \& those Hypotheses wch are not deduced from Phænomena by proper arguments. But if any man will take the word Hypothesis in a large sense, he may extend it, if he pleases to the impenetrability of matter the laws of motion \& the Axioms of Geometer. For it is not worth the while to dispute about the signification of a word. (Turnbull, e.a. (eds.) (1959-1977), vol. V, pp. 398-399 (= CUL Add. Ms. 3984.14, f. $1^{\mathrm{r}-\mathrm{v}}$ )

Judging by the tone of the original draft, which differs greatly from the succint and more formal style of the letter as sent, Cotes' remark about hypothesim fingere must have struck a nerve with Newton. In the draft version of this letter, Newton basically gave three different arguments that were to justify the application of Law III in Corollary 1 to Proposition Proposition V. First of all, he provided an ex negativo argument - a point which he also made in the letter as sent to Cotes, namely, if gravitationally interacting bodies did not attract each other equally in opposite directions, "both would go away together with a motion accelerated in infinitum", which is an absurdity since it "introduces a principle of self motion into bodies" and "would disturbe the whole frame of nature". However, this argument, taken by itself, offers no satisfactory answer to Cotes' worry: all it shows is that, if the attracting force of body $y_{1}$ was significantly unequal to the counteracting force of $b o d y_{2}$, both would be set in a uniformly accelerated and rectilinear motion, by the inequality of their interaction; it does not show that the counteracting force resides in the attracted body. Newton's two positive

\footnotetext{
${ }^{60}$ In the original "rational" is preceded by "Propesit" (ibid.).
} 
arguments are more to the point. Secondly, Newton pointed out that Law III was deduced from phenomena and that the application of this law in Corollary 1 was the result of a rendering general by induction by Rule III (cf. "Experimental philosophy argues only from phænomena, draws general conclusions from the consent of phænomena, \& looks upon the conclusion as general when ye consent is general without exception, tho the generality cannot be demonstrated a priori."). Newton's third argument is the most convincing: forces exerted by the invisible hand adduced by Cotes or forces exerted by the surrounding ether particles on the attracted $b o d y_{2}$, are causes that are not deduced from phenomena and therefore cannot have any force against arguments that are based inductive generalizations of causes properly deduced from phenomena - here we find a striking anticipation of Rule IV. The point Newton was making that proper causes, or verae causae, should have empirical support and be shown to be true and sufficient of their effects (cf. Rule I). Therefore, alternative causes not established along these criteria are merely hypothetical (cf. ibid., II, p. 400). Hence, Newton's words: "It is not enough to object that a contrary phænomenon may happen but to make a legitimate objection, a contrary phenomenon must be actually produced.". Newton's argument was then that, since no alternative forces had been established according to proper natural-philosophical standards ${ }^{61}$, and, furthermore, since the existence of a resistance yielding, i.e. mechanical, ether surrounding celestial bodies was very doubtful, the attractive counterforce can safely be assumed to reside in the attracted body. Although Newton's application of Law III in Corollary 1 of Proposition V was not a rigid deduction from phenomena (and Newton was clearly aware of that), it could be licensed by his rules of philosophizing and be considered as a legitimate induction generalization, until possible exceptions are observed. ${ }^{62}$

\subsection{Proposition VI: Weight-Mass Proportionality}

The main text of Proposition VI, in which Newton established weight-mass proportionality, remained virtually unaltered in all editions - important additions and corrections occurred, however, in its corollaries. Newton first established weight-mass proportionality for terrestrial bodies. The falling of bodies toward the earth takes place in equal times, "at least on making an adjustment for the inequality of the retardation of the air" (Newton 1999 [1726], p. 806). By means of pendulums Newton was able to determine the equality of the times more accurately. He performed such pendulum tests using nine different materials (gold, silver, lead, glass, sand, common salt, wood, water and wheat):

I got two wooden boxes, round and equal. I filled one of them with wood, and I suspended the same weight of gold (as exactly as I could) in the center of oscillation of the other. The boxes, hanging by equal eleven-foot cords, made pendulums exactly like each other with respect to to their weight, shape and air resistance. Then, when placed so close to each other [and set into vibration], they kept swinging back and forth together with equal oscillations for a very long time. (...) And it was so for the rest of the materials. In these experiments, in bodies of the same weight,

\footnotetext{
${ }^{61}$ This was the point Newton made in a letter to Leibniz: "For since celestial motions are more regular than if they arose from vortices and observe other laws, so much so that vortices contribute not to the regulation but to the disturbance of the motions of planets and comets; and since all phenomena of the heavens and of the sea follow precisely, so far as I am aware, from nothing but gravity acting in accordance with the laws described by me; and since nature is very simple, I have myself concluded that all other causes are to be rejected and that the heavens are to be stripped as far as may be of all matter, lest the motions of planets and comets be hindered or rendered irregular [ipse causas alias omnes abdicandas judicavi et cælos materia omni quantum fieri licet privandos ne motus Planetarum et Cometarum impediantur out reddantur irregulares]." (Newton to Leibniz, 16 October 1693, Turnbull, e.a. (eds.) (1959-1977), vol. III, pp. 285-289, p. 287 [italics added]).

${ }^{62}$ In other words, Newton was clearly of the ampliative nature of inductive generalizations.
} 
a difference of matter that would be even less than a thousandth part of the whole could been clearly noticed. (ibid., p. 807)

From Corollary 1 to Proposition XXIV of Book II (ibid., p. 700-701) ${ }^{63}$, it follows that $m_{1} / m_{2}::$ $\mathrm{F}_{m 1} / \mathrm{F}_{m 2}$, which was to be demonstrated. ${ }^{64}$ Newton then set out to establish mass-weight proportionality for planets, "for there is no doubt that the nature of gravity [natura gravitatis] toward the planets is the same as toward the earth" (cf. Rules II-IV) (ibid. p. 807). Newton backed this claim up by several arguments. From the moon test in Proposition IV, it follows that terrestrial bodies, "raised as far as the orbit of the moon and, together with the moon, deprived of all motion, to be released so far as to fall to the earth simultaneously", will in equal times describe equal spaces as the moon, so that their quantity of matter is to the quantity of matter of the moon as their weights are to the weight of the moon (ibid.). As we know from Proposition I of Book III, the accelerative forces of the satellites of Jupiter/Saturn vary inversely as the square of the distance from the centre of Jupiter/Saturn. Accordingly, in falling from equal heights in equal times they would describe equal spaces, so that their quantity of matter is to the quantity of matter of the Jupiter/Saturn as their weights are to the weight of Jupiter/Saturn (ibid.). The same argument holds for the primary planets. Furthermore, that the weights of the primary and secondary planets are to their quantities of matter follows by Corollary 3 to Proposition LXV of Book I (ibid., pp. 807-808). For, if they were more or less strongly attracted in proportion to their quantity of matter, then by Corollary 2, Proposition LXV their motions would be perturbed by the inequality of attraction, which is not the case. ${ }^{65}$

In its final edition, Proposition VI was followed by five corollaries. Corollaries 1-4 taken jointly can be seen as a polemic blow at Descartes' vortex cosmology - Corollary 2 is in fact the sole place in the Principia where Descartes is mentioned by name. There, Newton rebutted the Cartesian explanation of gravity (Corollaries 1-2) and the Cartesian plenum (Corollaries 24). In Corollary 1, which remained identical in all editions, Newton concluded that "the weights of bodies do not depend on their forms and textures [Hinc pondera corporum non pendent ab eorum formis \& texturis.]" (ibid., p. 809). "For", as Newton continued, "if the weights could be altered with the forms, they would be, in equal matter, greater or less according to the variety of forms, entirely contrary to experience" (ibid.). As a body's gravity is proportional to its quantity of matter, it remains unchanged in case the same amount of mass is preserved - irrespective of the body's form. Gravity therefore does not act on a body's surface (Descartes' claim), but on its quantity of matter. In Corollary 2, Newton stated that all bodies universally that are on or near the earth gravitate toward the earth and the weights of all bodies that are equally distant from the centre of the earth are proportional to their quantity of matter. Moreover, gravity is "a quality of all bodies on which experiments can be made and therefore by rule $3^{66}$ is to be affirmed of all bodies universally [Hæc est qualitas omnium in

\footnotetext{
${ }^{63}$ For a recent reconstruction of Newton's experiments, see Wilson 1999.

${ }^{64}$ Proposition XXIV of Book II established that $m_{1} / m_{2}::\left(\mathrm{F}_{\mathrm{m} 1} \times \mathrm{t}_{1}{ }^{2}\right) /\left(\mathrm{F}_{\mathrm{m} 2} \times \mathrm{t}_{2}{ }^{2}\right)$ obtains for swinging bodies. Since the times are equal, we derive $m_{1} / m_{2}:: \mathrm{F}_{\mathrm{m} 1} / \mathrm{F}_{\mathrm{m} 2}$ (Corollary 1$)$.

${ }^{65}$ As Harper points out: "Absence of such orbital polarization counts as a phenomenon measuring the equality of ratios of mass to weight toward the Sun at equal distances." (Harper 2002a, p. 189).

${ }^{66}$ In the second edition of the Principia, Rule III - which has often baffled interpreters - was introduced: "Those qualities of bodies that cannot be intended and remitted [i.e., qualities that cannot be increased and diminished] [intendi \& remitti nequeunt] and that belong [competent] to all bodies on which experiments can be made should be taken $^{66}$ [habenda sunt] as qualities of all bodies universally (Newton 1999 [1726], p. 795). At the end of the text to Rule III, Newton noted that gravity "diminishes as bodies recede from the earth" (ibid., p. 796). It may then be objected that Newton seems to be contradicting himself by claiming, on the one hand, that gravity cannot be increased and diminished (and therefore is a universal property), and, on the other hand, that gravity diminishes as a body recedes from the earth. However, the apparent contradiction on Newton's part easily disappears once we consider relevant manuscript material (post-1713, pre-1717): "All bodies here below are heavy towards $\mathrm{y}^{\mathrm{e}}$ Earth in proportion to the quantity of matter in $\downarrow$ each of $\downarrow$ them. Their gravity $\downarrow$ in proportion to their matter $\downarrow$ is not
} 
quibus experimenta instituere licet, \& propterea per reg. III. de universis affirmanda est]" ibid.). ${ }^{67}$ If you deny this, then either bodies are devoid of gravity or gravitate less in proportion to their quantity of matter. Now,

\begin{abstract}
If the aether or any other body whatever either were entirely devoid of gravity or gravitated less in proportion to the quantity of matter, then, since (according to the opinion of Aristotle, Descartes, and others) it does not differ from other bodies except in the form of its matter, it could by a change of its form be transmuted by degrees into a body of the same conditions as those that gravitate the most in proportion to the quantity of their matter; and, on the other hand, the heaviest bodies, through taking on by degrees the form of the other body, could by degrees lose their gravity. And accordingly the weights would depend on the forms of bodies and could be altered with the forms, contrary to what has been proved in corol. 1. (ibid., p. 809 [italics added])
\end{abstract}

In Corollary 3, Newton wrote that "[a]ll spaces are not equally full [Spatia omnia non sunt æqualiter plena.]" (ibid. p. 810) ${ }^{68}$ For if there were a fluid "with which the region of the earth would be filled, because of the extreme density of its matter," its specific gravity "would not be less than the specific gravity of quicksilver or of gold or of any other body with the greatest density, and therefore neither gold nor any other body could descend in air" (ibid.). Newton then added the suggestion that the ether could be diminished indefinitely. ${ }^{69}$ In Corollary 4 , which was added in the second edition of the Principia and taken over in the third edition, Newton provided yet another argument against the Cartesian plenum: "If all the solid particles of all bodies have the same density and cannot be rarefied without pores, there must be a vacuum [Si omnes omnium corporum particulæ solidæ sint ejusdem densitatis, neque absque poris rarefieri possint, vacuum datur.]" (ibid.). In Corollary $5^{70}$, Newton differentiated gravitational forces from magnetic ones - put differently: he showed that gravity and magnetism are forces of a different species:

\begin{abstract}
The force of gravity is of a different kind from the magnetic force [diversi est generis a vi magnetica]. For magnetic attraction is not proportional to the [quantity of] matter attracted. Some bodies are attracted [by a magnet] more [than in proportion to their quantity of matter], and others less, while most bodies are not attracted [by a magnet at all]. And the magnetic force in one and the same body can be intended and remitted [i.e., increased and decreased] [vis magnetica in uno $\&$ eodem corpore intendi potest et remitti] and is sometimes far greater in proportion to the quantity of matter than the force of gravity; and this force, in receding from the magnet, decreases not as the square but almost as the cube of the distance, as far as I have been able to tell from certain rough observations [ex crassis quibusdam observationibus animadvertere potui]. (ibid.) ${ }^{71}$
\end{abstract}

Magnetism is not a universal property, since it can intended and remitted. Neither are magnetic forces proportional to the quantity of matter attracted, nor do they vary inversely proportional to the distance.

\footnotetext{
intended or remitted $\downarrow_{\text {in }}$ the same region of the earth by any variety of $\downarrow$ fforms $\downarrow \downarrow$ \& therefore it cannot be taken away I speak of bodies equally distant from $y^{e}$-centre of the earth (...)" (CUL Add. Ms. 3970, f. 243" [italics added], cf. f. $253^{\mathrm{r}}$ ). In order to get further understanding of the meaning of "qualities that cannot be intended or remitted", it is useful to contrast them with qualities that can be intended and remitted. After having discussed the "vertue or disposition" of Island Crystal to produce double refraction, Newton noted: "And as magnetism may be intended \& remitted, \& and is found only in the Magnet \& in iron: so this vertue of refracting the perpendicular rays is greater in Island Crystal less in Crystal of the rock \& is not yet found in other bodies." (CUL Add. Ms. 3970 , f. $258^{\mathrm{r}}$ [post 1713, pre-1717]). Rule III instructs us to consider such qualities as qualities that pertain to all bodies universally.

${ }^{67}$ The argument based on Rule III as well as the reference to Aristotle and Descartes were added in the second edition and remained unaltered in the third edition.

${ }^{68}$ In the first edition, the first sentence of Corollary 3 was "Itaque Vacuum necessariò datur.".

${ }^{69}$ This final sentence to Corollary 4 was added in the second edition and remained unchanged in the third edition.

${ }^{70}$ Corollary 5 in the second and third edition correspond to Corollary 4 in the first edition.

${ }^{71}$ This corollary was identical in the second and third editions.
} 


\subsection{Proposition VII-VIII: Universal Gravitation}

Proposition VII, in which Newton argued for universal gravitation, is one of the few propositions of Book III that is identical in all editions of the Principia (ibid., pp. 810-811). Thus far, Newton had demonstrated that all planets gravitate towards each other and that the gravity toward any planet (taken by itself) varies inversely as the square of the distance of the places from the centre of that planet. By Proposition LXIX of Book I, it follows that the gravity towards all planets is proportional to their quantity of matter. Furthermore, since (1) all the parts of a planet A are heavy towards planet B, (2) the gravity of each part is to the gravity of the whole as the quantity of matter of that part to the quantity of matter of the whole, and (3) to every action there is an equal reaction (by Law III), it follows that planet B will gravitate in turn toward all the parts of A, and its gravity to any one part will be to its gravity toward the whole of the planet as the quantity of matter of that part to the quantity of matter of the whole (ibid., p. 811). Thus, as Newton continued in Corollary 1, the gravity toward the whole planet arises from and is compounded of the gravity of the individual parts ("Oritur igitur \& componitur gravitas in planetam totum ex gravitate in partes singulas."). ${ }^{72}$ From Corollary 3 to Proposition LXXIV of Book I - which proves that, if toward each of the separate points of a given (homogeneous) sphere there tend equal centripetal forces varying inversely proportional to the square of the distances from those points, a corpuscle placed outside the sphere is attracted by a force inversely proportional to the square of the distance of the corpuscle from the centre of this sphere - it furthermore follows that the gravity toward each of the individual particles of a body is inversely as the square of the distance of the places from those particles (Corollary 2). In order to back-up his argument for universal gravitation Newton required the demonstration that the overall inverse-square centripetal force exerted by a body results from the composition of each of the individual inverse-square centripetal forces of the particles constituting that body. The upshot of the propositions on the attractions of spherical surfaces is that the inverse-square law would hold exactly for perfect spheres with symmetrically distributed densities. ${ }^{73}$ By implication, if the inverse-square law does not hold exactly, then the body under consideration is either not perfectly spherical or it has no symmetrically distributed density. In other words, any deviation from the inverse-square law is seen as a deviation from perfect sphericity or symmetrical density distribution. In this sense, the conditions under which an exact mathematical relation would hold exactly become informative about the physical conditions that are producing deviations from the exact mathematical solution: if the areas described are not proportional to the times, it is not the case that only one centripetal force is urging a body exactly toward its centre of force (or, put positively, an additional force is affecting the situation); similarly, if the inverse-square law does not hold exactly, it is not the case that the body under consideration is perfectly spherical or has a symmetrical mass distribution.

In Proposition VIII, Newton observed:

I was still not certain whether that proportion of the inverse square obtained exactly in a total force compounded of a number of forces, or only nearly so [obtineret accurate in vi tota ex viribus

\footnotetext{
72 Newton noted: "If anyone objects that by this law all bodies on our earth would have to gravitate toward one another, even though gravity of this kind is by no means detected by our senses, my answer is that gravity toward these bodies is far smaller than what our senses could detect, since such gravity is to the gravity toward the whole earth as [the quantity of matter in each of] these bodies to the [quantity of matter in the] whole earth." (Newton 1999 [1726], p. 811).

${ }^{73}$ I refer to propositions of this type as micro inference-tickets, as they license conclusions about the inversesquare centripetal forces of the micro-particles that constitute a macroscopic body from the overall inversesquare centripetal force exerted by that body.
} 
pluribus composita, an vero quam proxime]. For it could happen that a proportion which holds exactly enough at very great distances [in majoribus distantiis satis accurate obtineret] might be markedly in error [notabiliter erraret] near the surface of the planet, because there the distances of the particles may be unequal and their situations dissimilar [ob inæquales particularum distantias $\&$ situs dissimiles]. But at length, by means of book 1, props. 75 and 76 and their corollaries [ibid., pp. 594-596], I discerned [intellexi] the truth of the proposition dealt with here. (ibid., p. 811)

From these corollaries, it follows that the inverse-square proportion is preserved all the way down to the surfaces of the attracting bodies. As a real tour de force, in Corollary 1 to Proposition VIII, Newton determined the proportion of the weight force on bodies of equal mass at equal distances from Jupiter, Saturn and the earth, respectively, to the weight force on bodies of equal mass at equal distances from the sun. ${ }^{74}$

\subsection{Understanding Universal Gravitation}

Newton's argument for universal gravitation contains several intelligibility enhancing virtues:

- Propositions I and II: by Newton's spelling out of the implications a Cartesian vortex cosmology he rendered it intelligible that mechanical theories cannot account for the celestial motions (negative aspect) and that a non-mechanical cause needs to be introduced in natural philosophy (positive aspect) (causal explanation).

- Proposition III-V: by the moon-test he gave insight in the fact that the motion of the moon, the motions of the primary and secondary planets, and the terrestrial motions are produced by the same force (unification + convergence of independently calculated theoretical parameters).

- Proposition VI: by applying the same argument pattern, which stated that, when acceleration is constant, mass-weight proportionality obtains, to the primary and secondary planets he made his readers understand that mass-weight proportionality obtains in celestial motions as well (unification).

- Proposition VII-VIII: by mathematically showing that an overall inverse-square force of a body is composed by the mathematical points composing this mathematical body, he made it clear that the individual particles composing a physical body result in an overall inverse-square force ((de)composition).

\section{From Huygens to de Regt and Dieks}

Among Newton's contemporaries Christiaan Huygens surely was one of the Principia's most able readers: on the one hand, he was highly skilled in mathematics, which enabled him to grasp the technicalities of the Principia (see, e.g.: Huygens 1888-1950, vol. XXI, pp. 408-426 and Huygens 1690, pp. 466-488), and, on the other hand, he had good physical insight enabling him to devise an experimentum crucis for deciding between Newton's theory of universal gravity and his own mechanical theory on the matter. ${ }^{75}$ Huygens found the notion of

\footnotetext{
${ }^{74}$ See Garisto 1991, Newton 1999 [1726], pp. 217-231, and Cohen 1998 for the details.

${ }^{75}$ Huygens' 1690 account of gravitation was a spherical-vortical account of gravitation which rejected Cartesian vortices. Cf.: “[...] je voudrais bien sçavoir si du depuis [i.e., since the publication of Newton's Principia in 1687] vous n'avez rien changé à vostre Theorie, parce que vous y faites entrer les Tourbillons de Mr. des Cartes, qui à mon avis sont superflus, si on admet le Systeme de Mr. Newton où le mouvement des Planetes s'explique par la pesanteur vers le Soleil et la vis centrifuga, qui se contrebalancent. Outre que ces Tourbillons Cartesiens faisoient naitre plusieurs difficultés, comme vous verrez pas mes remarques et mesme sans elles vous ne pouviez pas l'ignorer." (Huygens to Leibniz, 8 February 1690, Huygens 1888-1950, vol. IX, p. 368, cf. Huygens to
} 
gravitational attraction "absurd" (Huygens to Leibniz, 18 November 1690, Huygens 18881950, vol. IX, p. 538), i.e. unexplainable by any mechanical principle (Huygens 1690, p. 471), and at the outset of his Discours de la cause de la pesanteur (1690) he clarified why he thought so:

\begin{abstract}
Pour trouver une cause intelligible de la Pesanteur, il faut voir comment il se peut faire, en ne supposant dans la nature que des corps qui soient faits d'une mesme matiere, dans lesquels on ne considere aucune qualité ni aucune inclination à s'approcher les uns vers les autres, mais seulement des differentes grandeurs, figures, \& mouvements; comment, disje il se peut faire que plusieurs pourtant de ces corps tendent directement vers un mesme centre, \& s'y tienent assemblez à l'entour; qui est le plus ordinaire \& le principal phenomene de ce que nous appelons pesanteur. (Huygens 1690, p. 451 [italics added])
\end{abstract}

Correspondingly, Huygens explained gravity in mechanical terms, i.e. in terms of direct contact: when a body, which is immersed in a rapidly moving fluid consisting of small particles contained in a spherical space so that each particle of that fluid matter has a tendency to move away from the centre, does not follow the circular motion of the surrounding fluid or moves more slowly than the surrounding fluid, it will be pushed by the surrounding fluid towards the centre (Huygens 1690, pp. 452-462; see furthermore Snelders 1989, pp. 212-215). Although Huygens was genuinely impressed by physico-mathematical results of Newton's Principia (e.g. the inverse-square law and the derivation of Keplerian motion, the moon test, etc.), he could not accept the idea that bodies in a Boylian vacuum attracted one other:

\begin{abstract}
Je n'ay donc rien contre la Vis Centripeta, comme Mr. Newton l'appelle, par la quelle il fait peser les Planetes vers le Soleil, \& la Lune vers la Terre, mais j'en demeure d'accord sans difficulté: parce que non seulement on sçait par experience qu'il y a telle maniere d'attraction ou d'impulsion dans la nature, mais qu'aussi elle s'explique par les loix du mouvement, comme on a vû dans ce que j'ay écrit cy dessus de la pesanteur. Car rien n'empêche que la cause, de cette Vis Centripeta vers le Soleil, ne soit semblable à celle qui pousse les corps, qu'on appelle pesants, à descendre vers la Terre. (Huygens 1690, p. 472)
\end{abstract}

Huygens devised an experimentum crucis which was to settle the case between Newton's theory of universal gravitation and his own spherical-vortical explanation of gravity: namely, to explain why a seconds pendulum is shorter near the equator (i.e., to explain why in the same amount of time a pendulum traverses less space at the equator than elsewhere on the earth) - a difference that was first observed by Jean Richer in 1672-1673 when he compared the length of a seconds pendulum at Cayenne to one at Paris (Huygens to the Directors of the East Indian Company [Dutch: Vereenigde Oost-Indische Compagnie], 24 April 1688, Huygens 1888-1950, vol. IX, pp. 272-291; cf. Huygens 1690, pp. 462-471, pp. 476-484). According to Huygens, it was the earth's rotation at the equator alone that reduced the net effect of gravity and correspondingly he thought that the earth's centrifugal forces at the equator are sufficient to explain the different lengths of the seconds-pendulums. Newton's theory explained the difference as follows - on the assumption that the earth is a homogeneously dense, oblate, and fluid sphere, which is flattened by the centrifugal force of the earth's rotation. Surface gravity varies with latitude from the combination of two effects: (1) centrifugal effects by the earth's rotation plus (2) the gravitational forces at the earth's surface arising from their composition out of inverse-square forces directed toward the

Leibniz, 11 July 1692, ibid., vol. X, p. 297, cf. Huygens to Leibniz, 12 January 1693, ibid., vol. X, p. 385; for Huygens' reservations against Cartesianism, see: Huygens to G. Meier, June 1691, ibid., vol. X, pp. 104-105; cf. Huygens 1690, pp. 472-473; cf. Snelders, 1989, pp. 215-219). 
particles in an oblate earth (Newton 1999 [1726], pp. 821-832). ${ }^{76}$ By consequence, the variation of surface gravity with latitude is larger according to Newton's theory than according to Huygens'. In other words, measuring the variations of surface gravity could provide an answer to which gravitational theory was correct. Collecting trustworthy data to settle the matter turned a difficult matter for both Huygens and Newton (Schliesser \& Smith forthcoming; Greenberg 1996) and it was only in the eighteenth century that the issue was settled in favour of universal gravitation (Greenberg 1995). In any case, Newton understood the significance of what Huygens was doing as is clear from the many changes Newton incorporated in the second and third edition of the Principia.

There is a systematic lesson to be learned from this episode in the history of science which has implications for de Regt and Dieks proposal on scientific understanding. Recall that de Regt and Dieks claim that:

Not only skills of scientists but also properties of theories play a role in this dimension: whether scientists are able to apply a theory to a particular phenomenon depends both on their skills and on the pragmatic virtues of the theory, e.g., visualisability or simplicity. These virtues may contribute to the intelligibility of the theory, thereby facilitating the use of the theory in the construction and application of models, and accordingly they contribute to the achievement of the epistemic aims of science. The appropriate combination of scientists' skills and intelligibility-enhancing theoretical virtues is a condition for scientific understanding. (de Regt and Dieks 2005, p. 142 [italics added])

Moreover, when commenting on the qualitative understanding provided by Boyle's gas law, they note:

It is important to note that the above reasoning does not involve any calculations. It is based on general characteristics of the theoretical description of the gas. Its purpose is to give us understanding of the phenomena, before we embark on detailed calculations. Such calculations are subsequently motivated, and given direction, through the understanding we already possess. (ibid., pp. 152-153 [italics in original])

Because of his mechanicist assumptions Huygens found a key element of Newton's theory of universal gravitation unintelligible: the very notion of attraction. The notion of attraction did not fit into his mechanical worldview and he therefore considered explanations based on attractive forces as illegitimate and absurd. Despite all this, Huygens had a profound operative understanding of Newton's theory, i.e. he had a genuine grasp of what Newton's theory of universal gravitation encompassed and of how conclusions were to be derived from it. He certainly was mathematically skilled enough to penetrate into the specifics of Newton's propositions.

In the terminology of de Regt and Dieks, Huygens did not ascribe to the appropriate intelligibility-enhancing theoretical virtues to consider the theory of universal gravitation as an intelligible theory. Must we therefore conclude that Huygens could not understand and work with the theory of universal gravitation and the propositions of the Principia - for this is exactly what they suggest when they write that "calculations are subsequently motivated, and given direction, through the understanding we already possess [i.e. the understanding provided when a scientist qualifies a theory as an intelligible theory]'?

My answer is negative. As is particularly clear from his experimentum crucis, Huygens' was able to grasp the content of Newton's theory of universal gravitation, which states that all bodies attract one another in void space in proportion to their mass and inversely proportional to the distance from their centres, at a qualitative level, and, moreover, he was able to embark

\footnotetext{
${ }^{76}$ I shall refrain from going into the technical details of Newton's propositions on the shape of the earth, which often contained hidden steps and mathematical results which Newton did not bother to spell out (Greenberg 2006).
} 
in detailed calculations derived from the theory of universal gravitation, to reason with Newton's gravitational models, and to render Newton's qualitative claims empirically significant, despite his reservations against the idea of attraction. Therefore, de Regt and Dieks' criterion that the appropriate combination of scientists' skills and intelligibilityenhancing theoretical virtues is a condition for scientific understanding is too strong, and, moreover, contrary to what de Regt and Dieks claim, the subsequent quantitative phase of model construction needs not to be motivated by the previous acceptance of the intelligibility of a particular theory. The case of Newton-Huygens shows that, despite an unbalance between the appropriate combination skills and intelligibility-enhancing theoretical virtues, Huygens succeeded in getting both a qualitative and quantitative understanding of universal gravitation - and, vice versa, that Newton had a qualitative and quantitative understanding of Huygens' spherical vortex theory. Here we have a clear example of two scientists, who endorsed different worldviews and different criteria of what counts as an adequate scientific explanation, but who could nevertheless understand each others' theories both qualitatively and quantitatively.

Let me put it another way. If de Regt and Dieks' criterion was adequate, there would be a deep incommensurability between Newton's and Huygens' gravitational theories: since Newton and Huygens did not share the relevant intelligibility-enhancing theoretical virtues, both could not understand one another's theory qualitatively. Moreover, since de Regt and Dieks further more assume that further quantitative understanding requires that a theory should be seen as intelligible in the first place, Newton and Huygens could not understand each others' theories quantitatively. Given the discussion of the experimentum crucis above, I hope to have made the case that Newton and Huygens well understood each others' positions and that there was a genuine sense of communication between the adherents of two different theories. ${ }^{77}$ The moral is that scientists can understand each others' positions despite their endorsement of different worldviews and despite their convictions as what counts as a proper explanation.

\section{References:}

Aiton, E.J. (1972). The Vortex Theory of Planetary Motions. London/New York: MacDonald/American Elsevier.

Aoki, S. (1992). The Moon-Test in Newton's Principia: Accuracy of Inverse-Square Law of Universal Gravitation. Archive for History of Exact Sciences, 44, 147-190.

Aoki, S. (1996). Corrections and Additions for "The Moon-Test in Newton's Principia: Accuracy of InverseSquare Law of Universal Gravitation”, Archive for History of Exact Sciences. 94, 393-396.

Batens, D. (1985). Meaning Acceptance and Dialectics. In J.C. Pitt (ed.), Change and Progress in Modern Science (pp. 333-360). Dordrecht: Reidel.

Cohen, I.B. (1966). Hypotheses in Newton's Philosophy. Physis, 8, 163-184.

Cohen, I.B. (ed.) (1978 [1958]), Isaac Newton's Papers and Letters on Natural Philosophy. Cambridge (Mass.): Harvard University Press.

Cohen, I.B. (1982 [1980]). The Newtonian Revolution, with illustrations of the transformation of scientific ideas (second edition). Cambridge: Cambridge University Press.

Cohen, I.B. (1998). Newton's Determination of the Masses and Densities of the Sun, Jupiter, Saturn and the Earth. Archive for history of Exact Sciences, 53, 83-95.

Densmore, D. (1995). Newton's Principia: the Central Argument, Translation, notes, and expanded proofs. Santa Fe (New Mexico): Green Lion Press.

de Regt, H.W., \& Dieks, D. (2005). A contextual approach to scientific understanding. Synthese, 144, 137-170.

de Regt, H.W. (2004). Discussion note: Making sense of understanding. Philosophy of Science, 71, 98-109.

Ducheyne, S. (2005a). Newton's Training in the Aristotelian Textbook Tradition: From Effects to Causes and Back. History of Science, 43, 217-237.

\footnotetext{
${ }^{77}$ For a systematic outline of the idea of trans-theoretical communication, see Batens 1985.
} 
Ducheyne, S. (2005b). Newton's Notion and Practice of Unification. Studies in History and Philosophy of Science, $36 \mathrm{~A}, 61-78$.

Ducheyne, S. (2006). The General Scholium: Some notes on Newton's Published and Unpublished Endeavours. Lias: Sources and Documents Relating to the Early Modern History of Ideas, 33, 223-274.

Garisto, R. (1991). An Error in Isaac Newton's Determination of Planetary Properties. American Journal of Physics, 59, 42-48.

Gerhardt, C. I. (ed.) (1849-1863). G. W. Leibniz: Mathematische Schriften (7 vols.). Berlin/Halle: H.W. Smith.

Giere, R. N. (1988). Explaining Science: A Cognitive Approach. Chicago: University of Chicago Press.

Greenberg, J.L. (1995). The Problem of the Earth's Shape from Newton to Clairaut, The Rise of Mathematical Science in Eighteenth-Century Paris and the Fall of "Normal" Science. Cambridge: Cambridge University Press.

Greenberg, J.L. (1996). Isaac Newton and the Problem of the Earth's Shape. Archives for the History of Exact Sciences, 49, 371-391.

Harper, W. L. (2002a). “Newton's Argument for Universal Gravitation”. In I. B. Cohen \& G. E Smith (eds.), The Cambridge Companion to Newton (pp. 74-201). Cambridge: Cambridge University Press.

Harper, W. L. (2002b). "Howard Stein on Isaac Newton: Beyond Hypotheses". in: D.B. Malament (ed.), Reading Natural Philosophy: Essays in the History and Philosophy of Science and Mathematics to Honor Howard Stein on his $70^{\text {th }}$ Birthday (pp. 71-112). La Salle: Open Court.

Henry, J. (1994). "Pray do not Ascribe that Notion to Me": God and Newton's Gravity. In: J.E. Force \& R.H. Popkin (eds.), The Books of Nature and Scripture: Recent Essays on Natural Philosophy, Theology and Biblical Criticism in the Netherlands of Spinoza's Time and the British Isles of Newton's Time (pp. 123-147). Series: International Archives of the History of Ideas, vol. 139. Dordrecht: Kluwer.

Henry, J. (2007). Isaac Newton y el Problema de la Acción a Distancia. Estudios de filosofía, 35, 189-226.

Huygens, C. (1690). Discours de la cause de la pesanteur. In Huygens 1888-1950, vol. XXI (pp. 443-488).

Huygens, C. (1888-1950). Euvres complètes de Christiaan Huygens (edited by the Dutch Society of Sciences) (22 vols.). The Hague/Amsterdam: Martinus Nijhoff/Swets \& Zeitlinger.

Iliffe, R. (2004), Abstract Considerations: Disciplines and the Coherence of Newton's Natural Philosophy. Studies in History and Philosophy of Science, 35, 427-454.

Janiak, A. (ed.) (2005). Newton, Philosophical Writings. Cambridge: Cambridge University Press.

Janiak, A. (2007). Newton and the Reality of Force. Journal for the History of Philosophy, 45, 127-147.

Janiak, A. (2008). Newton as Philosopher. Cambridge: Cambridge University Press.

Koyré, A. (1965). Newtonian Studies. London: Chapman \& Hall.

Koyré, A., Cohen, I.B. \& Whitman, A. (eds.) (1972). Isaac Newton's 'Philosophiae Naturalis Principia Mathematica': The Third Edition (1726) with Variant Readings. Cambridge: Cambridge University Press.

McMullin, E.V. (1978). Newton on Matter and Activity. Notre Dame, University of Notre Dame Press.

McMullin, E.V. (1990). "Conceptions of science in the Scientific Revolution”. In R.S. Westman, \& D.C. Lindberg (eds.), Reappraisals of the Scientific Revolution (pp. 27-92). Cambridge: Cambridge University Press.

Morgan, M.S., \& Morrison, M. (eds.) (1999). Models as Mediators, Perspectives on Natural and Social Science. Cambridge: Cambridge University Press.

Newton, I. (1979 [1730]). The Opticks. New York: Dover.

Newton, I. (1999 [1726]). The Principia, Mathematical Principles of Natural Philosophy, A New Translation by I. Bernard Cohen and Anne Whitman, assisted by Julia Budenz, Preceded by A Guide to Newton's Principia by I. Bernard Cohen. Berkeley: University of California Press.

Pourciau, B.H. (2003). Newton's argument for Proposition 1 of the Principia. Archive for History of Exact Sciences, 57, 267-311.

Pourciau, B.H. (2009). Proposition II (Book I) of Newton's Principia. Archive for History of Exact Sciences, 63 , 129-167.

Russell, J.L. (1964). Kepler's Laws of Planetary Motion: 1609-1666. The British Journal for the History of Science, 2, 1-24.

Schliesser, E., \& Smith, G.E. (forthcoming). Huygens's 1688 Report to the Directors of the Dutch East Indian Company on the Measurement of Longitude at Sea and the Evidence it Offered Against Universal Gravity. Archive for History of Exact Sciences.

Shapiro, A.E. (2004). Newton's “Experimental Philosophy”. Early Science and Medicine, 9, 168-217.

Snelders, H.A.M. (1989). Christiaan Huygens and Newton's Theory of Gravitation. Notes and Records of the Royal Society of London, 43, 209-222.

Smith, G. E. (1999). The Motion of the Lunar Apsis. In Newton, 1999 [1726] (pp. 257-264).

Spencer, Q. (2004). Do Newton's rules of reasoning guarantee truth ... must they? Studies in History and Philosophy of Science, 35, 759-782. 
Stein, H. (1970). On the Notion of Field in Newton, Maxwell, and Beyond. In R.H., Stuewer (ed.), Historical and Philosophical Perspectives on Science (pp. 264-287). Series: Minnesota Studies in the Philosophy of Science, vol. 5. Minneapolis: University of Minnesota Press.

Stein, H. (1990). "From the Phenomena of Motions to the Forces of Nature": Hypothesis or Deduction. PSA: Proceedings of the Biennial Meeting of the Philosophy of Science Association 1990, Volume II: Symposia and Invited Papers, 209-222.

Thoren, V.E. (1974). Kepler's Second Law in England. British Journal for the History of Science, 9, 243-258.

Trout, J.D. (2002). Scientific Understanding and the Sense of Understanding. Philosophy of Science, 69, 212-233.

Trout, J.D. (2005). Paying the Price for a Theory of Explanation: De Regt's Discussion of Trout. Philosophy of Science, 72, 198-208.

Turnbull, H.W. e.a. (eds.) (1959-1977). The Correspondence of Isaac Newton (7 vol.). Cambridge, Cambridge University Press.

Valluri, S.R., Wilson, C., \& Harper, W.L. (1997). Newton's Apsidal Precession Theorem and Eccentric Orbits. Journal for the History of Astronomy, 28, 13-27.

Westfall, R.S. (1973). Newton and the Fudge Factor. Science 179 ( ${ }^{\circ}$ 4075), 23 February, 751-758.

Whiteside, D.T. (1964). Newton's Early Thoughts on Planetary Motion: A Fresh Look. British Journal for the History of Science, 2, 117-37.

Whiteside, D.T. (1970). Before the Principia: The Maturing of Newton's Thought on Dynamical Astronomy, 1666-1684. Journal for the History of Astronomy, 1, 5-19.

Whiteside, D.T. (1976). Newton's Lunar Theory: From High Hope to Disenchantment. Vistas in Astronomy, 19, 317-328.

Whiteside, D.T. (ed.) (1967-1981). The Mathematical Papers of Isaac Newton (8 vols.). Cambridge, Cambridge University Press.

Whiteside, D.T. (1991). The Prehistory of the Principia from 1664 to 1686 . Notes and Records of the Royal Society of London, 45, 11-61.

Wilson, C. (1974). Newton and Some Philosophers on Kepler's "Laws". Journal of the History of Ideas, 35 , 231-258.

Wilson, C. (1989). The Newtonian Achievement in Astronomy. In R. Taton \& C. Wilson (eds ), Planetary Astronomy from the Renaissance to the Rise of Astrophysics: Tycho Brahe to Newton (pp. 233-274). Cambridge: Cambridge University Press.

Wilson, C. (1999). Re-doing Newton's Experiment for Establishing the Proportionality of Mass and Weight. The St. John's Review, 45, 64-73.

Wilson, C. (2000). Newton on the Moon's Variation and Apsidal Motion: The Need for a Newer 'New Analysis'. In J.Z. Buchwald \& I.B. Cohen (eds.), Isaac Newton's Natural Philosophy (pp. 139-188). Series: Dibner Institute Studies in the History of Science and Technology. Cambridge (Mass.), MIT Press. 